\title{
Development and Validation of a Novel Reporter Assay for Human Papillomavirus Type 16 Late Gene Expression
}

\author{
Beatrice Orru \\ Technological University Dublin, beatrice.orru@mydit.ie \\ Ciaran Cunniffe \\ Technological University Dublin, ciaran.cunniffe@mydit.ie \\ Fergus Ryan \\ Technological University Dublin, fergus.x.ryan@tudublin.ie
}

See next page for additional authors

Follow this and additional works at: https://arrow.tudublin.ie/scschbioart

Part of the Biology Commons, Molecular Genetics Commons, Virology Commons, and the Virus Diseases Commons

\section{Recommended Citation}

Orru, B., Cunniffe, C., Ryan, F., Schwartz, S. (2012). Development and Validation of a Novel Reporter Assay for Human Papillomavirus Type 16 Late Gene Expression. Journal of Virological Methods, 183(2), pp.106-16. doi:10.1016/j.jviromet.2012.03.023

This Article is brought to you for free and open access by the School of Biological Sciences at ARROW@TU Dublin. It has been accepted for inclusion in Articles by an authorized administrator of ARROW@TU Dublin. For more information, please contact arrow.admin@tudublin.ie, aisling.coyne@tudublin.ie,gerard.connolly@tudublin.ie. Funder: Strand III

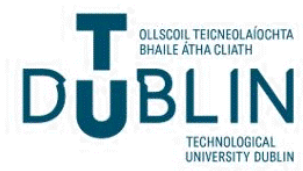




\section{Authors}

Beatrice Orru, Ciaran Cunniffe, Fergus Ryan, and Stefan Schwartz 


\section{Development and validation of a novel reporter assay for human papillomavirus type 16 late gene expression}

Beatrice Orrù, Ciaran Cunniffe, Fergus Ryan*, Stefan Schwartz§

Dublin Institute of Technology, Kevin Street, Dublin 8, Ireland

30 pages

"Corresponding author. Mailing address:

Fergus Ryan PhD.

School of Biological Sciences

Dublin Institute of technology

Kevin Street

Dublin 8

Ireland

Phone: +35314024564

Fax: +35314024834

e-mail: fergus.x.ryan@dit.ie

§present address: Department of Laboratory Medicine, Section of Medical Microbiology, Lund University, BMC-B13, room B1314c, 22184 Lund, Sweden. 


\section{Summary}

To facilitate the investigations of HPV-16 late gene expression HPV-16 reporter plasmids were generated using previously described sub-genomic HPV-16 plasmids, named pBEL and pBELM, that, similar to the full viral genome, produce primarily HPV-16 early mRNAs and very little, if any, late mRNAs in cervical cancer cells. The HPV-16 late L1 gene was replaced by the chloramphenicol acetyltransferase (CAT) reporter gene, or green fluorescent protein (GFP), preceded by the poliovirus internal ribosome entry site (IRES). Results show that the reporter genes mimic the expression of L1 from these plasmids. For example, overexpression of adenovirus E4orf4 protein (E4orf4), polypyrimidine tract binding protein (PTB), arginine/serinerich SRp30c protein (SRp30c) or alternative splicing factor/splicing factor 2 (ASF/SF2) induced an increased expression of CAT or GFP. Stable cell lines with reporter plasmids pBELCAT and pBELMCAT were also generated. An induction of CAT was observed in HPV-16 reporter cell lines in the presence of the small molecule phorbol 12-myristate 13-acetate (TPA). Further experiments identified the TPA-inducible, hnRNP A2/B1 protein as a regulator of HPV-16 late gene expression. In conclusion, the HPV-16 reporter plasmids and reporter cell lines described herein can be used to identify small molecules and cellular factors that regulate HPV-16 gene expression.

Key words: HPV-16, splicing, hnRNP A2/B1, TPA, ASF/SF2, SR proteins, novel reporter assay 


\section{Introduction}

Cervical cancer is the second leading cause of death by cancer in women worldwide after breast cancer (WHO, 2006). Persistence of human papillomaviruses (HPVs) infection is a prerequisite for development of cervical cancer or pre-malignant lesions that could progress to cancer (Lowy, 2001; Zur Hausen, 2002). HPVs are subdivided into high risk and low risk groups and HPV type 16 (HPV-16) is the most common high-risk type that is present in approximately $50 \%$ of all cervical cancers (Munoz et al., 2003). HPV-16 gene expression is strictly dependent on cellular differentiation with late HPV16 genes expressed only in differentiating cells. HPV-16 late gene expression is not detected in cervical cancer cells containing HPV-16 DNA (Doorbar, 2005; Longworth and Laimins, 2004; Ozbun et al., 2007). Late genes encode the highly immunogenic structural proteins, $L 1$ and $L 2$, and their production in the lower layers of the infected epithelium is strongly suppressed, possibly to prevent detection by the host immune system (Schwartz et al., 2007). It has been shown that processing of HPV-16 mRNAs is highly regulated (Graham, 2008; Schwartz, 2008; Zheng and Baker, 2006). HPV-16 splice donor SD3632 and splice acceptor SA5639 (Fig. 1A-B) are used exclusively by the late mRNAs and splicing silencers suppress the use of these splice sites in cervical cancer cells (Rush et al., 2005; Zhao et al., 2007; 2004). HPV-16 late gene expression is also indirectly inhibited by RNA elements that stimulate early mRNA splicing (Rush et al., 2005) and polyadenylation (Oberg et al., 2005; 2003; Terhune et al., 1999; Zhao et al., 2005). It was speculated that premature induction of HPV-16 late gene expression in the persistently 
infected cells would alert the immune system of the presence of the virus and that this immune activation could clear the infection. It is therefore of interest to understand how HPV-16 late gene expression is regulated.

In previous studies two subgenomic HPV-16 expression plasmids were described carrying the viral early and late genes, except E6 and E7, driven by the strong human cytomegalovirus (CMV) immediate early promoter, called pBEL and pBELM (Zhao et al., 2004) (Fig. 1B). When these plasmids are transfected into HeLa cells, they express HPV-16 early, but not late genes. It has been shown that overexpression of a number of viral and cellular proteins, such as adenovirus E4orf4 protein (E4orf4), cellular polypyrimidine tract binding protein (PTB) and members of the serine-arginine rich protein family, induce late gene expression in both pBEL and pBELM (Somberg et al., 2011; 2009; 2008; Somberg and Schwartz, 2010).

In order to facilitate the identification of cellular factors that regulate HPV-16 late gene expression, pBEL-derived plasmids were generated by us containing easily detectable reporter genes, such as CAT and GFP, in place of HPV-16 L1 (Figs. 1C, 1D and 1E). Stable cell lines harbouring these plasmids were generated and characterised. As proof of concept, it was demonstrated that the small molecule TPA could activate CAT expression from these reporter cell lines, and hnRNP A2/B1 protein was identified as a novel regulator of HPV-16 late gene expression. 


\section{MATERIALS AND METHODS}

\subsection{Plasmid construction}

pBEL, pBELM, have been described previously (Zhao et al., 2004). In order to construct the reporter plasmids pBELCAT and pBELMCAT, PCR was first performed with oligonucleotides IRESs and IRESa (Table 1) to amplify the IRES sequence of poliovirus $2 \mathrm{~A}$. The PCR fragment was subcloned into pCR2.1-TOPO (Invitrogen, Paisley, Scotland) and then transferred as a BamHI-Xhol fragment into PBEL and PBELM, generating pBEL-IRES and pBELM-IRES (Fig. 1C), respectively, with the IRES sequence replacing all but the first 514-nucleotides of the L1 sequence in PBEL and PBELM. The chloramphenicol acetyltransferase (CAT) sequence was first PCR amplified with primers CATs and CATa (Table 1) and cloned into pCR2.1-TOPO. The CAT sequence was excised with Mlul and Xhol and inserted downstream the IRES sequence in pBEL-IRES and PBELM-IRES to generate pBELCAT and pBELMCAT (Fig. 1D). pBspliceCAT and pBspliceMCAT were generated by digestion of pBELCAT and pBELMCAT, respectively with BssHII-Sall followed by filling in of overhangs with T4 DNA polymerase and relegation (Fig. 4A). To construct pMT1sdCAT, a HindIII-Apal fragment from plasmid pMT1sd (Somberg et al., 2008) was inserted into pBELMCAT (Fig. 4A). To generate pBSPtatLTRCAT and pBSPMtatLTRCAT a DNA sequence encoding a modified HIV-1 tat gene in which the $3^{\prime}$-splice sites of rev and and nef exons $4 a, 4 b, 4 c$ and 5 had been mutationally inactivated, followed by the HIV-1 HXB2R LTR sequence and a codon optimised GFP coding was purchased from GenScript (Piscataway, USA). The DNA sequence was delivered as a pUC57 plasmid with the ordered insert that was named pUC57/tat/LTR/GFP. 
This sequence was inserted into pBspliceCAT and pBspliceMCAT using BssHII and Xhol. The GFP gene was replaced by CAT using Mlul and Xhol, resulting in pBSPtatLTRCAT and pBSPMtatLTRCAT (Fig. 4A).

The plasmid pCMVCAT was constructed by cleaving pBELCAT with Sall and BamHI, filling in of overhangs and religation. In order to construct pBELMGFP (Fig. 1E), the GFP sequence from pUC57/tat/LTR/GFP was transferred to pBELM-IRES as a Mlul-Xhol fragment (Fig. 1E). Plasmids pCMVE4orf4 (Somberg et al., 2009), pCMVPTB (Somberg et al., 2008), pASF/SF2 (Somberg and Schwartz, 2010) and pCMVSRp30c (Somberg et al., 2011), have been described previously.

\subsection{Transfections and cell culture}

HeLa cells were cultured in RPMI-1640 medium containing $10 \%$ fetal bovine calf serum, glutamine and penicillin-streptomycin. Transfections were carried out by using GeneJuice $® T$ ransfection reagent according to the protocol of the manufacturer (Novagen, Merck KGaA, Darmstadt, Germany). Cells were transfected with each plasmid in a minimum of three independent experiments.

A second reporter vector, pCH110, (Amersham, Little Chalfont, UK) expressing the $\beta$-galactosidase gene under the control of an SV40 promoter, was included in transfection experiments as an internal control to normalise CAT levels. For transfections with pCMVGFP and pBELMGFP expression plasmids, cells were cultured on cover slips placed into the wells of $60-\mathrm{mm}$ plates. $2 \times 10^{6} \mathrm{HeLa}$ cells were plated in each well. 


\subsection{Establishment of stable cell lines}

$1.5 \mu \mathrm{g}$ of each of pBELCAT or pBELMCAT were cotransfected with $0.25 \mu \mathrm{g}$ of pSV2NEO into HeLa cells and stable clones were selected in the presence of $200 \mu \mathrm{g} / \mathrm{ml}$ of G418 (Roche Diagnostics, Sussex, UK). Individual clones were picked and plated in new cell culture dishes. To extract DNA from the clones, cells were lysed with a $25 \mathrm{mM}$ EDTA, $2 \%$ SDS solution and proteins were precipitated with $2.5 \mathrm{M}$ ammonium acetate solution. The DNA was precipitated with isopropanol and washed with $70 \%$ ethanol. The DNA pellet was resuspended in TE buffer (10mM Tris-Cl pH8.0, 1mM EDTA) and subjected to PCR amplification with CATs and CATa primers (Table 1). $15 \mu \mathrm{l}$ of each PCR product were analysed on $1 \%$ agarose gels.

\subsection{RNA extraction and reverse transcription (RT)-PCR}

Total RNA was isolated using the High pure RNA isolation kit according to the protocol of the manufacturer (Roche Diagnostics, Sussex, UK). Total RNA was then reverse transcribed at $42^{\circ} \mathrm{C}$ by using Superscript II and gene specific primers (Table 1) according to the manufacturer's instructions (Invitrogen, Paisley, Scotland). $2 \mu$ of cDNAs were PCR-amplified in a $25 \mu \mathrm{l}$ reaction volume using oligonucleotides listed in Table 1. The DNA was denatured at $94^{\circ} \mathrm{C}$ and extended at $72^{\circ} \mathrm{C}$ in all $\mathrm{PCR}$ reactions, while annealing temperature differed. An annealing temperature of $55^{\circ} \mathrm{C}$ was used to PCR amplify cDNAs with 757 s and E4a primers (Zhao et al., 2004), whereas an annealing temperature of $57^{\circ} \mathrm{C}$ was used with primers $757 \mathrm{~s}$ and L1Ma primers (Zhao et al., 2005). cDNA synthesized with oligonucleotide 
CATa was PCR amplified with an annealing temperature of $68^{\circ} \mathrm{C}$ with primers 757s and CATa.

\subsection{CAT ELISA}

Cells were harvested 24 hours post-transfection and lysed in $1 \mathrm{ml}$ of lysis buffer, and the CAT levels were determined using a CAT ELISA assay according to the protocol of the manufacturer (Roche Diagnostics, Sussex, UK). Absorbance was measured at $405 \mathrm{~nm}$ using a 96-well microplate ELISA reader (Fisher Scientific, Loughborough, UK).

\subsection{GFP detection and quantitation}

For the analysis of pCMVGFP and pBELMGFP expression plasmids, cells were washed twice with PBS 24 hours post-transfection and the cover slips were removed from the wells and mounted on slides. GFP fluorescence intensities were detected and quantitated with a fluorescence microscope from the living cells (CELL^^ ${ }^{\wedge}$ software, Olympus, Hamburg, Germany).

\subsection{Western blot analysis}

Cells were harvested in $1 \mathrm{ml}$ of lysis buffer. Equal amounts of protein were separated by SDS-PAGE and then transferred onto nitrocellulose membrane by electroblotting. The blots were probed with mouse hnRNP A2/B1 antihnRNP A2/B1 monoclonal antibody (Abcam, Cambridge, UK) diluted 1:1000. Mouse anti- $\beta$ actin antibody was purchased from Sigma. Membranes were incubated with horseradish peroxidase-conjugated secondary antibodies against mouse (Sigma Aldrich, Wicklow, Ireland). Proteins were revealed with 
an enhanced chemiluminescence kit (Thermo Scientific - Pierce, Dublin Ireland). 


\section{RESULTS}

\subsection{Generation of subgenomic HPV-16 reporter plasmids pBELCAT, PBELMCAT and PBELMGFP}

In order to generate a simple and reliable bioassay to study HPV-16 late gene expression, two previously described plasmids named pBEL and pBELM (Zhao et al., 2004) were used (Fig. 1B). These subgenomic HPV-16 constructs carry viral early and late genes, except that the E6 and E7 genes and the early and late promoters are replaced by the strong human cytomegalovirus (CMV) immediate early promoter (Fig. 1B). Similar to the HPV-16 genome, pBEL transfected into proliferating cells expresses high levels of the early genes, primarily E4 mRNAs, whereas expression of late genes L1 and L2 is barely detectable (Zhao et al., 2004). In the mutant version of $p B E L$, named $p B E L M$, splicing silencers present in the L1 region have been inactivated by multiple point mutations (Fig. 1B), and late L1 mRNAs are expressed in transfected cells, but at a relatively low level (Zhao et al., 2004).

To replace part of the HPV-16 L1 gene in pBEL and pBELM with an easily detectable reporter gene, the poliovirus $2 \mathrm{~A}$ internal ribosome entry site (IRES) was first inserted between BamHI at position 6150 in HPV-16 L1 and nucleotide position 7272 in the HPV-16 late UTR. This resulted in plasmids pBEL-IRES and pBELM-IRES (Fig. 1C). These plasmids retain SA5639 and the first 514-nucleotides of the L1 coding sequence that contain RNA elements that regulate splicing to SA5639 (Figs. 1B and 1C). The IRES sequence was followed by a short polylinker that allows insertion of various reporter genes downstream of IRES. The CAT gene was first inserted, 
resulting in pBELCAT and pBELMCAT (Fig. 1D). CAT serves as a marker for L1 and L2 expression and can be monitored by CAT ELISA assay. pBELCAT and pBELMCAT were transfected into HeLa cells and CAT expression was monitored 24 hours post-transfection. pBELCAT produced barely detectable levels of CAT (0.13 CAT units) (Fig. 2A), whereas pBELMCAT showed higher CAT expression (29 CAT units) (Fig. 2A) as expected. pBELMCAT produced over 200-fold more CAT than pBELCAT (Fig. 2A). However, these levels of CAT were relatively low compared to CAT expression from the positive control plasmid CMVCAT, which produced 10,600 CAT units (Fig. 2A). These results demonstrated that only a minority of the mRNAs produced by pBELCAT and pBELMCAT were late mRNAs, suggesting that late gene expression was relatively inefficient from both plasmids. The multiple nucleotide substitutions in the first 514 nucleotides of L1 enhanced CAT expression in pBELMCAT as a result of the inactivation of splicing silencers as previously described (Zhao et al., 2004). These results demonstrated that the reporter plasmids pBELCAT and PBELMCAT were functional and expressed detectable levels of CAT protein in a manner that reflected the previously described production of HPV16 late mRNAs from the $\mathrm{pBEL}$ and $\mathrm{pBELM}$ plasmids. Plasmids pBELCAT and pBELMCAT could therefore be used to investigate HPV-16 gene expression.

\subsection{Adenovirus E4orf4, polypyrimidine tract binding protein, SRp30c and} ASF/SF2 induce CAT expression from pBELCAT and pBELMCAT reporter plasmids

HPV-16 late gene expression is regulated at the level of RNA processing (Graham, 2008; Schwartz, 2008; Zheng and Baker, 2006). It has been 
previously shown by us that overexpression of some viral and cellular proteins, e. g. adenovirus E4orf4 protein (E4orf4), polypyrimidine tract binding protein (PTB), serine/arginine-rich protein (SRp30c) and alternative splicing factor/splicing factor 2 (ASF/SF2), can induce HPV-16 late gene expression from pBEL and pBELM (Somberg et al., 2011; 2009; 2008; Somberg and Schwartz, 2010). In order to validate the functionality of the novel reporter plasmids pBELCAT and pBELMCAT, each reporter plasmid was cotransfected with E4orf4, PTB, SRp30c or ASF/SF2 expression plasmids into HeLa cells. Overexpression of E4orf4, PTB, SRp30c or ASF/SF2 caused an increase in CAT expression from both pBELCAT and pBELMCAT (Fig. 2B). E4orf4, which regulates the switch from early to late gene expression in the adenovirus life cycle (Akusjarvi and Stevenin, 2003), efficiently induced CAT production from both plasmids, but in particular from pBELCAT, resulting in a 300 fold induction of CAT (Fig. 2B). A titration of the E4orf4-, PTB-, SRp30c- or ASF/SF2-plasmids on each sub-genomic HPV-16 expression plasmid pBELCAT and pBELMCAT revealed that induction of CAT was dependent on the amount of transfected expression plasmid (Fig. 2C). While CAT induction caused by PTB and SRp30c increased with higher levels of PTB or SRp30c plasmid, the highest concentrations of E4orf4 plasmid inhibited CAT production, suggesting other effects of E4orf4 on the cells (Fig. 2C). It has been previously shown by us that low levels of ASF/SF2 induced HPV-16 late gene expression whereas high levels did not (Somberg and Schwartz, 2010). Transfection of pBELMCAT with serially diluted ASF/SF2 plasmid revealed a similar effect (Fig. 2C), further demonstrating that expression of the CAT reporter gene is a marker for HPV-16 late mRNA 
production. It was concluded that E4orf4, PTB, SRp30c and ASF/SF2 induced CAT expression from pBELCAT and pBELMCAT in a plasmid-dose dependent manner.

Next the CAT gene was replaced with a reporter gene that was easier and less expensive to detect. CAT was replaced with a humanized GFP ORF. It was reasoned that GFP levels produced from the pBEL-backbone would be too low to detect, and therefore only pBELMGFP was constructed (Fig. 1E). To investigate if pBELMGFP expresses detectable levels of GFP, pBELMGFP was transfected into HeLa cells in parallel with a positive control plasmid named pCMVGFP. Analysis of the transfected cells under fluorescence microscope revealed few or visible positive cells in the dishes transfected with pBELMGFP compared to the high number of GFP positive cells seen in the positive control and that the positive cells transfected with pBELMGFP fluoresced with a lower intensity that those transfected with pCMVGFP (Fig. 3A). This is expected when considering that pBELMCAT produced approximately 365-fold lower CAT levels than the positive control plasmid pCMVCAT (Fig. 2A). Few positive cells were detected when pBELMGFP was cotransfected with E4orf4, SRp30c or PTB (Fig. 3A). Therefore the CELL^F software (Olympus Soft Imaging solutions $\mathrm{GmbH}$ ) fluorescence microscope was used to monitor the intensity of fluorescence in 10 individual randomly chosen, positive cells in each transfection. These results revealed that GFP levels produced from pBELMGFP were approximately 200 -fold lower than those produced by pCMVGFP (Fig. 3B). This is in line with the difference in CAT production between pBELMCAT and pCMVCAT (Fig. 2A). Co- 
transfection of pBELMGFP with E4orf4 showed little induction compared to cotransfections of pBELMGFP with PTB- or SRp30c-expression plasmids (Fig. 3C). PTB and SRp30c increased the levels of GFP by 6 - and 30- fold, respectively (Fig. 3C). Taken together these results demonstrated that the pBELMGFP reporter plasmid is functional and that it could potentially be used for fast and easy identification of cellular factors that could induce HPV-16 late gene expression. While the sensitivity of the GFP reporter in transient transfection assays is low, we believe that a stable cell line generated with pBELMGFP would allow reliable and sensitive detection of factors influencing HPV16 late gene expression.

\subsection{The HPV-16 CAT reporter plasmids can be used to identify and characterise cis-acting regulatory RNA elements}

Two viral splice sites are used exclusively by HPV-16 late mRNAs: late 5'splice site SD3632 (located in the early region) and late 3'-splice site SA5639 (located in the $\mathrm{L} 1$ coding region) (Fig. 1A). Both splice sites are suppressed by multiple splicing silencer elements (Schwartz, 2008). To investigate further how the reporter plasmids presented here could be used to study HPV-16 late gene expression, a set of simpler plasmids was generated containing the late region with the CAT reporter gene, but only the two splice sites SD3632 and SA5639. These plasmids were named pBspliceCAT and pBspliceMCAT (Fig. 4A). Transfection of these plasmids into HeLa cells revealed that CAT levels produced from pBspliceCAT were undetectable, whereas pBspliceMCAT expressed low, but detectable levels of CAT (1.6 CAT units) (Fig. 4B). These results confirmed that SD3632 and SA5639 are efficiently suppressed in 
cervical cancer cells. In addition, pAE may further suppress late gene expression from these plasmids. Transfection of pBspliceMCAT into HeLa

cells in the presence of plasmids expressing E4orf4, PTB or SRp30c, resulted in an induction of CAT production (Fig. 4C), but this induction was lower than the induction of CAT from pBELMCAT by the same proteins. In addition deletion of a previously described sequence that suppressed SD3632 (Rush et al., 2005; Somberg et al., 2008) as in plasmid pMT1sdCAT (Fig. 4A), resulted in efficient production of high levels of CAT (155 CAT units) (Fig. 4B). These results demonstrated that this set of plasmids could be used to study cis-acting, splicing regulatory elements at the HPV-16 late splice sites.

\subsection{Plasmids that amplify the levels of HPV-16 late mRNAs}

Since expression of CAT from plasmids pBspliceCAT and pBspliceMCAT (Fig. 4A) was so low, especially from pBspliceCAT from which CAT expression was undetectable, a set of plasmids was generated based on pBspliceCAT and pBspliceMCAT on which late gene expression should be amplified to yield a CAT signal. To do this, the CAT segment in these two plasmids was replaced with a DNA segment encoding the HIV-1 tat gene, followed by the HIV-1 long terminal repeat (LTR), which contains the HIV-1 polyadenylation signal (Harrich et al., 1989). However, this LTR also contains the full HIV-promoter followed by the CAT reporter gene and the late HPV-16 polyadenylation signal. The new plasmids were named pBSPtatLTRCAT and pBSPMtatLTRCAT (Fig. 4A). Transcription from the HIV-1 LTR is totally dependent on the HIV-1 transcriptional activator tat (Sheridan et al., 1993). If 
mRNAs are spliced into HPV-16 late splice site SA5639, the mRNAs are polyadenylated at the HIV-1 LTR and express HIV-1 tat protein from the poliovirus IRES. As tat is made, it activates the HIV-1 LTR promoter to produce CAT mRNA. Activation of the HIV-1 LTR by HIV-1 tat is in the range of 200 -fold and this additional step should therefore amplify the CAT signal that represents HPV-16 late mRNA splicing. Transfection of serially diluted pBSPtatLTRCAT and pBSPMtatLTRCAT plasmids into HeLa cells, revealed that CAT production was easily detectable from pBSPtatLTRCAT which contains two wild type HPV-16 splice sites (Fig. 4D), and does not produce detectable levels of CAT in the absence of that tat-based mRNA amplification. Plasmid pBSPMtatLTRCAT which contains mutations in L1 that destroyed splicing silencers produced substantially higher levels of CAT than its nonamplified sister plasmid pBspliceMCAT (Fig. 4D). CAT expression from the two HIV-1 tat-amplified plasmids pBSPtatLTRCAT and pBSPMtatLTRCAT was dependent on the amount of transfected plasmid. Therefore plasmids pBSPtatLTRCAT and pBSPMtatLTRCAT, in which minute levels of late mRNAs are amplified to allow detection with CAT ELISA, could be used to study the regulation of HPV-16 late splice sites SD3632 and SA5639.

\subsection{Establishment of two novel HPV-16 reporter HeLa cell lines, named pBELCAT-67 and pBELMCAT-31, that can serve as tools to investigate regulation of HPV-16 gene expression}

To establish stable cell lines containing the reporter plasmids pBELCAT or pBELMCAT, these plasmids were separately introduced into HeLa cells in the presence of plasmid pSV2neo, which encodes the neomycin-resistant gene 
under control of the SV40 promoter. As described in material and methods, cells were propagated in G418 to select for cells with integrated plasmid DNA. As shown in Figure 5, a number of clones were isolated and tested for CAT activity. CAT expression was barely detectable in pBELCAT cell lines (0.0020.3 CAT units). In contrast, significant levels of CAT were detected in pBELMCAT-derived cell lines (20-570 CAT units) (Fig. 5). The results revealed that stable cell lines carrying PBELCAT produced low or undetectable levels of CAT, whereas the pBELMCAT-derived cell lines produced higher levels of CAT, as expected. CAT levels in pBELCAT- and pBELMCAT-derived stable cell lines reflected the CAT levels produced by these plasmids in transient transfections.

To confirm that the integrated pBELCAT and pBELMCAT plasmids produced the expected early and late mRNAs, RNA was extracted and subjected to RTPCR. Total RNA was extracted and cDNA synthesized using the three different gene specific primers E4a, L1Ma and CATa, (Table 1 and Fig. 6). RT-PCR on cDNA from two selected cell lines named pBELCAT-67 and pBELMCAT-31 with primers 757s and E4a (Table 1) yielded a single 190bpband in both cell lines, representing E4 mRNAs produced by splicing from SD880 to SA3358 (Figs. 6A and 6D), as expected. In contrast, different results were observed when cell lines pBELCAT-67 and pBELMCAT-31 were analysed for production of late mRNAs. RT-PCR performed on pBELCAT-67 using 757s and L1a or 757s and CATa primers (Table 1), revealed that none of the late mRNAs could be detected, as expected (Fig. 6D). PCR on cDNA obtained from cell line pBELMCAT-31, using primers 757s and L1Ma (Table 1), resulted in two spliced products; one 430bp cDNA representing the L1 
mRNA that is spliced between SD880 and SA3358 and SD3632 and SA5639, and one 160bp cDNA representing the L1i mRNA that is spliced from SD880 to SA5639 (Fig. 6B). This result was expected as the pBELMCAT-31 cell line produced relatively high levels of CAT protein. cDNA synthesized with CATa primer was PCR amplified with primers 757 s and CATa primers (Table 1) yielding one major band of 2000bp representing a direct splice from SD880 to SA5639 (Fig. 6C). These results demonstrated that correctly spliced HPV-16 early and late mRNAs were produced in an expected manner, corroborating the integrity of the reporter plasmids in the stable reporter cell lines. To evaluate the functionality of these two novel stable cell lines, they were transfected with plasmids expressing adenovirus E4orf4, PTB or SRp30c. In the presence of these viral or cellular proteins, an increase of CAT expression was observed in pBELCAT-67- and pBELMCAT-31-derived cells. The induction was 10-, 5- and 3.4-fold respectively for E4orf4, PTB and SRp30c in the pBELCAT-67 cell line (Fig. 7), and 1.7-, 1.6- and 1.5-fold respectively in the pBELMCAT-31 cell line (Fig. 7). Induction of CAT produced was lower compared to transient transfections, however the results demonstrate that stable reporter cell lines pBELCAT-67 and pBELMCAT-31 could be used to study cellular factors that regulate HPV-16 gene expression.

\subsection{Treatment of stable cell lines pBELCAT-67 and pBELMCAT-31 with phorbol 12-myristate 13-acetate (TPA) induces HPV-16 late gene expression}

To provide evidence for the utility of the stable HPV-16 reporter cell lines pBELCAT-67 and pBELMCAT-31, it was investigated if these cell lines could 
be used to identify small molecules that can induce HPV-16 late gene expression. To this end cells were treated with TPA (phorbol 12-myristate 13acetate), a small substance that has been shown to induce HPV-31 late gene expression (Meyers et al., 1992). Treatment of stable cell lines pBELCAT-67 and pBELMCAT-31 with TPA resulted in an increase of CAT expression in a TPA-dose-dependent manner in both cell lines (Fig. 8A, left panel). Highest induction was obtained with pBELCAT-67. To control for possible effects of TPA on cellular protein synthesis, a western blot for actin was performed and demonstrated that TPA had no effect on actin levels (Fig. 8A, right panel). In contrast, other small molecular drugs such as emetine and N-Hexanoyl-Dsphingosine (ceramide), which have been shown to induce apoptosis by interfering with splicing (Boon-Unge et al., 2007) had no or an inhibitory effect on late gene expression in both cell lines (Fig. 8B). It was concluded that induction of CAT from pBELCAT-67 and pBELMCAT-31 was specific for the small molecule TPA and that the cell lines can be used to study the effect of small molecules and drugs on late gene expression.

\subsection{Identification of hnRNP A2/B1 as a regulator of HPV-16 late gene expression using the HPV-16-derived CAT reporter assay}

It has been demonstrated that TPA induces the expression of a number of genes that are involved in splicing in particular SC35 (serine/arginine-rich splicing factor 2) and hnRNP A2/B1 (Zheng et al., 2002). Western blot analysis confirmed an induction of hnRNP A2/B1 by TPA (Fig. 9A). However, hnRNP A2/B1 levels were unaffected by emetine and ceramide (Fig. 9A). It was investigated if overexpression of SC35 or hnRNP A2/B1 could induce 
HPV-16 late gene expression. CMV promoter driven plasmids expressing SC35 or hnRNP A2/B1 were cotransfected with HPV-16-derived CAT reporter plasmids pBELCAT or pBELMCAT. As can be seen in Figure 9B, overexpression of hnRNP A2/B1 caused a robust induction of CAT in both reporter plasmids, whereas SC35 induced very little CAT, and only from pBELCAT (Fig. 9B). A two-fold serial dilution of hnRNP A2/B1 resulted in a dose-dependent induction of CAT from both reporter plasmids (Fig. 9C). High levels of hnRNP A2/B1 did not induce CAT expression whereas lower levels efficiently induced CAT in both pBELCAT and pBELMCAT (Fig. 9C). In conclusion, HPV-16 derived reporter plasmids PBELCAT and pBELMCAT and reporter cell lines pBELCAT-67 and pBELMCAT-31 could be used to identify novel factors that regulate HPV-16 late gene expression. 


\section{Discussion}

Late HPV gene expression is regulated at the transcriptional and posttranscriptional levels (Schwartz, 2008; Zheng and Baker, 2006). Alternative splicing is necessary to produce L1 since the $3^{\prime}$ end of L2 and the $5^{\prime}$ end of L1 overlap. It has been previously shown that the L1 sequence of HPV-16 contains inhibitory RNA elements (Collier et al., 2002) and that late gene expression is also inhibited in mitotic cells because of a competition between early and late splice sites (Rush et al., 2005). In fact, inactivation of the E4 enhancer and the L1 splicing silencers in a subgenomic HPV-16 plasmid showed production only of L1 mRNA (L1i), but not E4 mRNA (Rush et al., 2005; Schwartz et al., 2007). Cellular RNA binding factors and viral RNA elements have shown to have a pivotal role in HPV-16 gene regulation (Johansson, 2011; Mole et al., 2006; Schwartz et al., 2007).

The aim of this study was to generate a set of reporter constructs based on previously described plasmids, $\mathrm{pBEL}$ and $\mathrm{pBELM}$, to aid in the investigation of HPV-16 late gene expression. This resulted in the production of pBELCAT and pBELMCAT. Evaluation of CAT expression levels from these plasmids revealed that pBELCAT, as expected, produced very little CAT, whereas pBELMCAT, in which mutations that reduce the negative regulation of splicing are present, efficiently expressed CAT. These results confirmed that splice site SA5639 has a pivotal role in regulation of late gene expression. In the presence of E4orf4, PTB, SRp30c and ASF/SF2, CAT was induced from both reporter plasmids. In particular Ad E4orf4, which regulates the switch from early to late gene expression in Adenovirus (Akusjarvi and Stevenin, 2003), 
showed a higher induction of CAT expression in PBELCAT when compared to the pBELMCAT plasmid. This difference is probably due to the high CAT levels produced by pBELMCAT in the absence of inducer plasmids. In addition, it has been shown that Ad E4orf4 overcomes the negative effect of splicing silencers present in the L1 region (Somberg et al., 2009). Since in pBELMCAT, these inhibitory elements had been inactivated by multiple point mutations, the viral protein can no longer target them and positively influence late gene expression as strongly as it is observed in pBELCAT. When the inducers of CAT expression were cotransfected with pBELMCAT, higher levels of CAT were observed with the higher concentration of PTB and SRp30c, respectively. In contrast, E4orf4 decreased CAT expression at higher concentrations; a result that might be correlated to other studies where adenovirus E4orf4 had shown to induce apoptosis (Kleinberger, 2000; Kornitzer et al., 2001; Roopchand et al., 2001). Taken together, these data clearly show that induction of CAT expression is dependent on the levels of regulatory proteins. By identifying hnRNP A2/B1 as a novel regulator of HPV16 late gene expression, the functionality of the novel HPV-16 derived reporter plasmids described herein in identifying proteins that regulate HPV16 late gene expression was demonstrated. Using the constructs discussed above only HPV-16 sequences were analysed. The reporters could be easily modified to examine other HPV types by replacing a Sall - BamHI from the reporters (containing the HPV-16 sequences) with the same sequences from other HPV types.

The reporters were also constructed using the luciferase gene and proved equally sensitive in transient transfections. The CAT assay used in this study 
benefits from the fact that it is based on an ELISA and unlike the luciferase assay is not based on function. It is therefore not influenced by external factors such as freeze thawing that can significantly affect assays based on function. Since the CAT assay was sensitive and reliable and suitable for large scale screening, this reporter was chosen for the generation of the stable cell lines and continued study.

Identification and characterisation of viral cis-acting RNA elements will also be facilitated using HPV-16 reporter plasmids. First, the difference in CAT expression between pBELCAT and pBELMCAT demonstrating that the assay detects mutated inactivation of splicing silencers in HPV-16 L1. Second, the difference in CAT expression between pMT1sdCAT and pBspliceMCAT was 95-fold. This difference was due to the deletion of splicing silencer upstream of SD3632, and demonstrated that pBspliceMCAT can be used to study these inhibitory sequences further. Therefore these plasmids could easily be used to identify and characterise cis-acting regulatory RNAs elements in HPV-16 genome.

In order to ensure reproducible, long-term and defined gene expression of the reporter plasmids, stable cell lines with pBELCAT and pBELMCAT integrated in their cellular genome were generated, named pBELCAT-67 and pBELMCAT-31. CAT expression could be induced from these cell lines by transient transfections of plasmids expressing viral and cellular proteins. However, CAT induction levels were lower compared to the induction levels obtained when CAT reporter plasmids were cotransfected with plasmids expressing proteins. Treatment of pBELCAT- and pBELMCAT-derived cell 
lines with TPA showed an increase of CAT levels in both cell lines, demonstrating that it will be possible to use these reporter cell lines to identify small molecules that can induce HPV-16 late gene expression. It was concluded that cell line pBELCAT-67 was particularly interesting as it primarily produces HPV-16 E4 mRNA, whereas late mRNAs were undetected, unless cells were transfected with TPA (Fig. 10). For that reason, these reporter cell lines may be more suitable to identify small molecules that effect HPV-16 late gene expression.

In conclusion, IRES-driven CAT and GFP genes in place of the late L1 gene in subgenomic HPV-16 plasmids proved to be functional surrogate markers for HPV-16 late gene expression in HeLa cells. Furthermore, functional stable cell lines with these plasmids were established that will be useful for the identification of cellular proteins, small molecules or microRNAs that regulate HPV-16 gene expression (Fig. 10). Such substances could potentially be used as antiviral drugs to treat persistent HPV infections.

\section{ACKNOWLEDGEMENTS}

We wish to thank Xiaoze Li and Monika Somberg for providing plasmids and Brid Ann Ryan for continuous support. Dr. Goran Akusjärvi for pASF/SF2, pCMV-SRp30c and pCMVE4orf4 plasmids, Dr. Clare Gooding for pCMVPTB1 and Dr. Oriol Bachs for hnRNP A2/B1.

This research was sponsored by Technological Sector Research, Strand III (Ireland) and Science Foundation Ireland (SFI). Stefan Schwartz is an SFIfunded stokes professor at Dublin Institute of Technology. Swedish Cancer Society and Swedish Research Council/Medicine. 


\section{References}

Akusjarvi, G., Stevenin, J., 2003. Remodelling of the host cell RNA splicing machinery during an adenovirus infection. Curr. Top. Microbiol. Immunol. 272, 253-286.

Boon-Unge, K., Yu, Q., Zou, T., Zhou, A., Govitrapong, P., Zhou, J., 2007. Emetine regulates the alternative splicing of $\mathrm{Bcl}-\mathrm{x}$ through a protein phosphatase 1-dependent mechanism. Chemistry \& biology 14, 13861392.

Collier, B., Oberg, D., Zhao, X., Schwartz, S., 2002. Specific inactivation of inhibitory sequences in the $5^{\prime}$ end of the human papillomavirus type 16 $L 1$ open reading frame results in production of high levels of $L 1$ protein in human epithelial cells. J. Virol. 76, 2739-2752.

Doorbar, J., 2005. The papillomavirus life cycle. J. Clin. Virol. 32, 7-15.

Graham, S.V., 2008. Papillomavirus 3'UTR regulatory elements. Front. Biosci. 13, 5646-5663.

Harrich, D., Garcia, J., Wu, F., Mitsuyasu, R., Gonazalez, J., Gaynor, R., 1989. Role of SP1-binding domains in in vivo transcriptional regulation of the human immunodeficiency virus type 1 long terminal repeat. J. Virol. 63, 2585-2591.

Johansson, C., Somberg, M., Schwartz, S., 2011. Proteins involved in HPV16 pre-mRNA processing. In "Current Topics in Virology", Research Signpost 8, 17-27.

Kleinberger, T., 2000. Induction of apoptosis by adenovirus E4orf4 protein. Apoptosis 5, 211-215.

Kornitzer, D., Sharf, R., Kleinberger, T., 2001. Adenovirus E4orf4 protein induces PP2A-dependent growth arrest in Saccharomyces cerevisiae and interacts with the anaphase-promoting complex/cyclosome. J. Cell Biol. 154, 331-344.

Longworth, M.S., Laimins, L.A., 2004. Pathogenesis of human papillomaviruses in differentiating epithelia. Microbiol. Mol. Biol. Rev. 68, 362-372.

Lowy, D.R., Howley, P.M. 2001. Papillomaviruses. In: D.M. Knipe, Howley, P.M. et al. (Ed), Fields Virology, Lippincott, Williams and Wilkins vol.2, pp. 2231-2264.

Meyers, C., Frattini, M.G., Hudson, J.B. , Laimins, L.A., 1992. Biosynthesis of human papillomavirus from a continuous cell line upon epithelial differentiation. Science 257, 971-973. 
Mole, S., Veerapraditsin, T., McPhillips, M.G., Graham, S.V., 2006.

Regulation of splicing-associated SR proteins by HPV-16. Bioc. Soc.

Trans. 34, 1145-1147.

Munoz, N., Bosch, F.X., De Sanjose, S., Herrero, R., Castellsague X., Shah, K.V., Snijders, P.J.F., Meijer, C.J.L.M., 2003. Epidemiologic classification of human papillomavirus types associated with cervical cancer. N. Engl. J. Med. 348, 518-527.

Oberg, D., Fay, J., Lambkin, H., Schwartz, S., 2005. A downstream polyadenylation element in human papillomavirus type $16 \mathrm{~L} 2$ encodes multiple GGG motifs and interacts with hnRNP H. J. Virol. 79, 92549296.

Oberg, D., Collier, B., Zhao, X., Schwartz, S., 2003. Mutational inactivation of two distinct negative RNA elements in the human papillomavirus type 16 L2 coding region induces production of high levels of $L 2$ in human cells. J. Virol. 77, 11674-11684.

Ozbun, M., Campos, S.K., Smith, J.L., 2007. The early events of human papillomavirus infections: implications for regulation of cell tropism and host range. Human papillomavirus gene regulation and transformation. Transworld Research Network, Trivandrum, India, 69-122.

Roopchand, D.E., Lee, J.M., Shahinian, S., Paquette, D., Bussey, H., Branton, P.E., 2001. Toxicity of human adenovirus E4orf4 protein in Saccharomyces cerevisiae results from interactions with the Cdc55 regulatory B subunit of PP2A. Oncogene 20, 5279-5290.

Rush, M., Zhao, X., Schwartz, S., 2005. A splicing enhancer in the E4 coding region of human papillomavirus type 16 is required for early mRNA splicing and polyadenylation as well as inhibition of premature late gene expression. J. Virol. 79, 12002-12015.

Schwartz, S., 2008. HPV-16 RNA processing. Front. Biosci. 13, 5880-5891.

Schwartz, S., Somberg, M., Zhao, X., Rush, M., Oberg, D., Cassidy, H., Fay, J., Lambkin, H., 2007. Regulation of HPV gene splicing and expression. Human papillomavirus gene regulation and transformation. Transworld Research Network, Trivandrum, India, 47-67.

Sheridan, P.L., Sheline, C.T., Milocco, L.H., Jones, K.A., 1993. Tat and the HIV-1 promoter: a model for RNA-mediated regulation of transcription. Seminars in Virology Vol. 4, 69-80.

Somberg, M., Li, X., Johansson, C., Orru, B., Chang, R., Rush, M., Fay, J., Ryan, F., Schwartz, S., 2011. Serine/arginine-rich protein 30c activates human papillomavirus type 16 L1 mRNA expression via a bimodal mechanism. J. Gen. Virol. 92, 2411-2421.

Somberg, M., Schwartz, S., 2010. Multiple ASF/SF2 Sites in the Human Papillomavirus Type 16 (HPV-16) E4-Coding Region Promote Splicing to the Most Commonly Used 3'-Splice Site on the HPV-16 Genome. J. Virol. 84, 8219-8230.

Somberg, M., Rush, M., Fay, J., Ryan, F., Lambkin, H., Akusjarvi, G., Schwartz, S., 2009. Adenovirus E4orf4 induces HPV-16 late L1 mRNA production. Virology 383, 279-290.

Somberg, M., Zhao, X., Frohlich, M., Evander, M., Schwartz, S., 2008. PTB induces HPV-16 late gene expression by interfering with splicing inhibitory elements at the major late 5'-splice site SD3632. J. Virol., 82, 3665-3678. 
Terhune, S.S., Milcarek, C., Laimins, L.A., 1999. Regulation of human papillomavirus type 31 polyadenylation during the differentiationdependent life cycle. J. Virol. 73, 7185-7192.

World Health Organization. Reproductive, H., World Health Organization. Chronic, D. and Health, P., 2006. Comprehensive cervical cancer control: a guide to essential practice. WHO.

Zhao, X., Fay, J., Lambkin, H., Schwartz, S., 2007. Identification of a 17nucleotide splicing enhancer in HPV-16 L1 that counteracts the effect of multiple hnRNP A1-binding splicing silencers. Virology 369, 351-363.

Zhao, X., Oberg, D., Rush, M., Fay, J., Lambkin, H., Schwartz, S., 2005. A 57nucleotide upstream early polyadenylation element in human papillomavirus type 16 interacts with hFip1, CstF-64, hnRNP C1/C2, and polypyrimidine tract binding protein. J. Virol. 79, 4270-4288.

Zhao, X., Rush, M., Schwartz, S., 2004. Identification of an hnRNP A1dependent splicing silencer in the human papillomavirus type $16 \mathrm{~L} 1$ coding region that prevents premature expression of the late $\mathrm{L} 1$ gene. J. Virol. 78, 10888-10905.

Zheng, X., Ravatn, R., Lin, Y., Shih, W.C., Rabson, A., Strair, R., Huberman, E., Conney, A., Chin, K.V., 2002. Gene expression of TPA induced differentiation in HL-60 cells by DNA microarray analysis. Nucleic acids research 30, 4489-4499.

Zheng, Z.M., Baker, C.C., 2006. Papillomavirus genome structure, expression, and post-transcriptional regulation. Front. Biosci. 11, 22862302.

Zur Hausen, H., 2002. Papillomaviruses and cancer: from basic studies to clinical application. Nat. Rev. Cancer 2, 342-350. 
Table 1 Sequences of oligonucleotides used in this study

\begin{tabular}{ll}
\hline Oligonucleotide & Sequence (5'-3') \\
\hline IRESs & GGGATCCTTAAAACAGCTCTGGGGTTG \\
IRESa & CCTCGAGTTAACACGCGTAGGTAATTCCAATAGGTGTGAGTG \\
CATs & GACGCGTACCATGAGTAAAGGAGAAGAACTTTTCACTGGA \\
CATa & CCTCGAGCTATTTGTATAGTTCATCCATGCC \\
$757 s$ & GTCGACGGTATCGATCGGTTGTGCGTACAAAGCACACACG \\
E4a & CCGCGCGCTGCCTAATAATTTCAGGAGAGG \\
L1a & CGCTGGGCAGCCACAGGC \\
L1Ma & \\
\hline
\end{tabular}




\section{Figures legend}

Fig. 1 (A) Schematic representation of the HPV-16 genome and (B, C, D, E) the subgenomic HPV-16 reporter plasmids used to study late gene expression. The early and late viral promoters, p97 and p670, and the early and late polyadenylation signals $\mathrm{pAE}$ and $\mathrm{pAL}$ are shown. The position of the human cytomegalovirus immediate early (CMV) promoter in the reporter plasmids is shown. Boxes indicate protein-coding regions. Black circles indicate splice donors (5' splice sites) and white circles indicate splice acceptor (3' splice sites). Numbers refer to nucleotide positions in the HPV-16 sequence. Major potential mRNAs that can be produced are shown. $M$ indicates previously described mutations that inactivate splicing silencers downstream of SA5639 (Zhao, et al., 2004). IRES: poliovirus 2A internal ribosome entry site. CAT: chloramphenicol acetyltransferase. GFP: humanised green fluorescent protein.

Fig. 2 (A) CAT levels in HeLa cells transiently transfected with pBELCAT, pBELMCAT or CMVCAT. The graph has a logarithmic scale. (B) Cotransfection of CAT reporter plasmids, pBELCAT or pBELMCAT, with E4orf4, PTB, SRp30c or ASF/SF2 expression vectors. (C) Two-fold titration of $1 \mu \mathrm{g}$ of E4orf4, PTB, SRp30c or ASF/SF2 expression plasmids cotransfected with pBELMCAT reporter plasmid. CAT unit was defined as absorbance in CAT ELISA times the dilution factor of the tested cell extracted. Cells were transfected with each plasmid in a minimum of three independent experiments. ( $p$-value $<0.05$ ).

Fig. 3 (A) HeLa cells were transfected with pCMVGFP, pBELMGFP, pBELMGFP + E4orf4, pBELMGFP + PTB or pBELMGFP + SRp30c. Untransfected cells are shown as a comparison. (B) Determination of GFP levels in individual cells in transient transfections with pCMVGFP or pBELMGFP expression plasmid. Note the logarithmic scale. (C) Quantitation of GFP expression in pBELMGFP in the absence or presence of E4orf4, PTB and SRp30c. GFP fluorescence intensities were detected and quantitated in 10 randomly chosen cells as described in Material and Methods. Cells were transfected with each plasmid in a minimum of three independent experiments. ( $p$-value<0.05). 
Fig. 4 (A) Schematic representation of subgenomic expression plasmids pBspliceCAT, pBspliceMCAT, pMT1sdCAT and pBSPtatLTRCAT. Black circles indicate splice donors (5' splice sites) and white circles indicate splice acceptor (3' splice sites). Numbers refer to nucleotide positions in the HPV-16 sequence. The early and late HPV-16 polyadenylation signals $p A E$ and $p A L$ are indicated. Major potential mRNAs produced by pBspliceMCAT, pMT1sdCAT and pBSPtatLTRCAT are indicated below the plasmids. E4* refers to a short mRNA encoding E4 and E5 that is unspliced due to the absence of SD880. (B) CAT levels produced in HeLa cells transfected with pBspliceCAT, pBspliceMCAT or pMT1sdCAT. (C) Fold induction of CAT from pBspliceMCAT transfected in the absence or presence of E4orf4, PTB or SRp30c plasmids. Transfections were carried out in triplicate. ( $p$-value<0.05). (D) CAT levels produced by transfected serial dilutions of plasmids pBSPtatLTRCAT or pBSPMtatLTRCAT in HeLa cells.

Fig. 5 (A) Determination of CAT levels in HeLa cell clones stably transfected with pBELCAT or pBELMCAT. CAT levels were determined by CAT ELISA. CAT levels in the graph are displayed with a logarithmic scale.

Fig. 6 Analysis of mRNAs produced by stable cell lines pBELMCAT-31 and pBELCAT-67. RT-PCR amplification of $(A)$ the early CMV $\rightarrow$ E4 region with 757s-E4a primers in pBELMCAT-31 and (D) pBELCAT-67, (B) the late region CMV $\rightarrow$ L 1 with 757s-L1Ma primers and (C) CMV $\rightarrow$ CAT with 757s-CATa primers in pBELMCAT-31 and (D) pBELCAT-67.

Fig. 7 Induction of CAT expression by transfection of plasmids expressing E4orf4, PTB or SRp30c into cell lines pBELCAT-67 or pBELMCAT-31. The graph shows average values obtained from a minimum of three independent transfection experiments. ( $p$-value<0.05).

Fig. 8 (A, left panel) Analysis of CAT expression in pBELCAT-67 and pBELMCAT-31 stable cell lines in the absence or presence of TPA; (A, right panel) actin levels on pBELCAT-67. (B) Determination of CAT levels in pBELCAT-67 or pBELMCAT-31 treated with emetine dihydrochloride hydrate or N-Hexanoyl-D-sphingosine (ceramide). A control of $0.5 \mu \mathrm{L}$ DSO was included. Transfections were carried out in triplicates.

Fig. 9 (A) Western blot analysis of levels of hnRNP A2/B1 on pBELCAT-67 stable cell line in the absence or presence of emetine, ceramide or TPA. (B) Induction of CAT levels in HeLa cells transiently transfected with pBELCAT and pBELMCAT in the absence or presence of plasmids expressing SC35 or hnRNP A2/B1. Transfections were carried out in triplicates. ( $p$-value<0.05). (C) Two-fold serial dilution of $2 \mu \mathrm{g}$ of hnRNP A2/B1 expression plasmid was cotransfected with pBELCAT or pBELMCAT. CAT levels were determined and plotted in the graphs.

Fig. 10 Schematic representation of the major potential mRNAs produced by pBELCAT-67 stable cell line in the absence or presence of TPA, Ad E4orf4, PTB or SRp30c. 


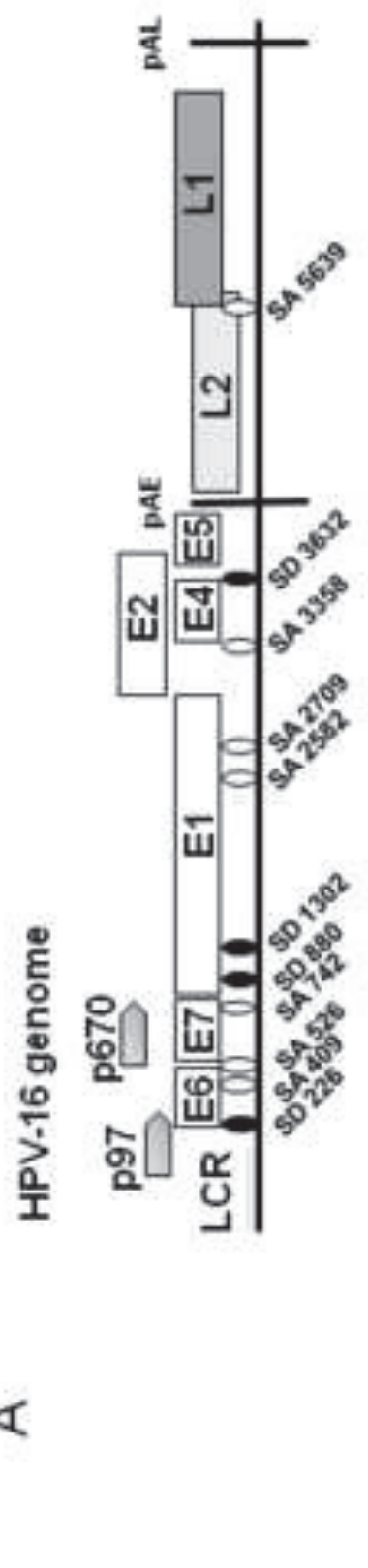




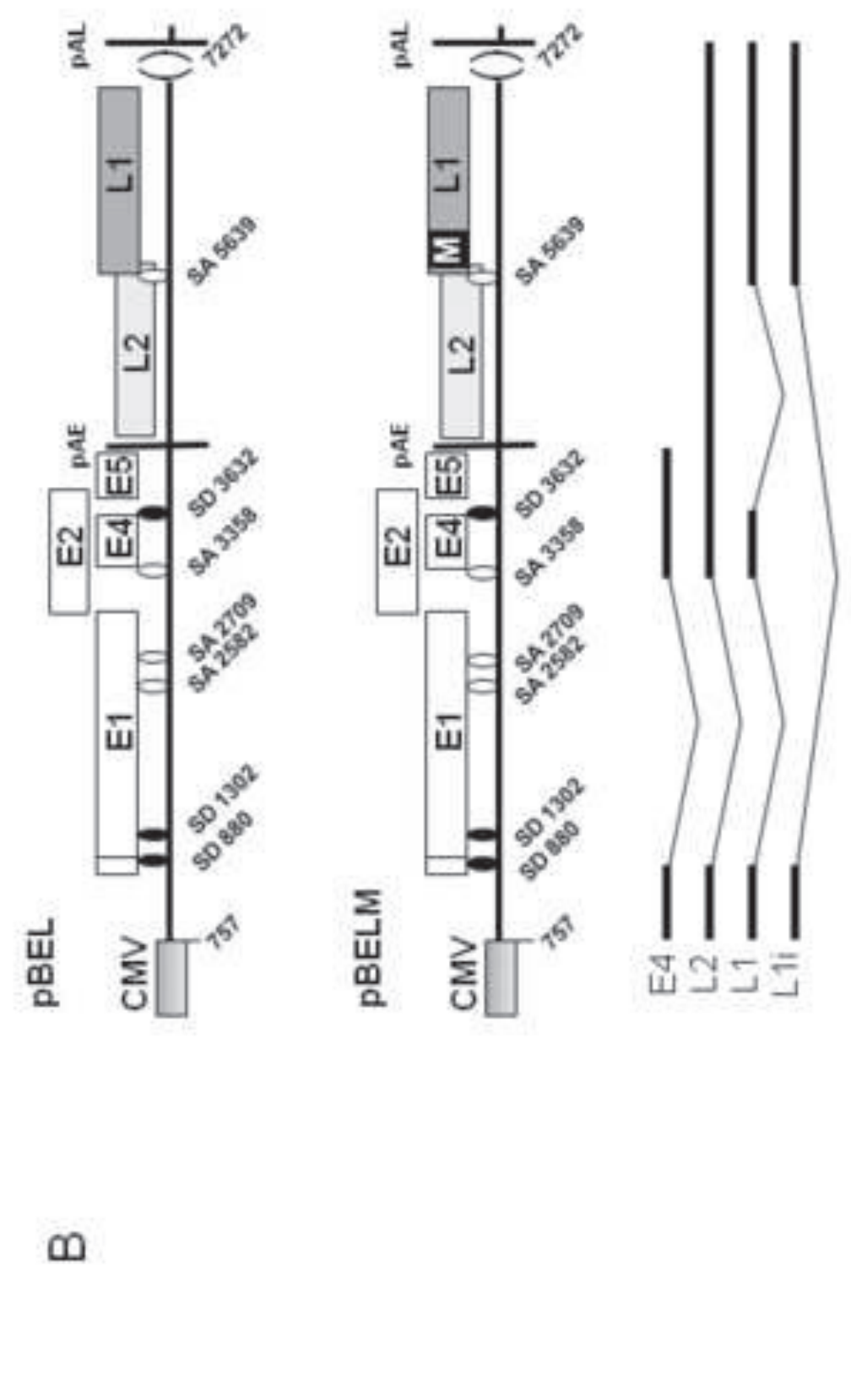



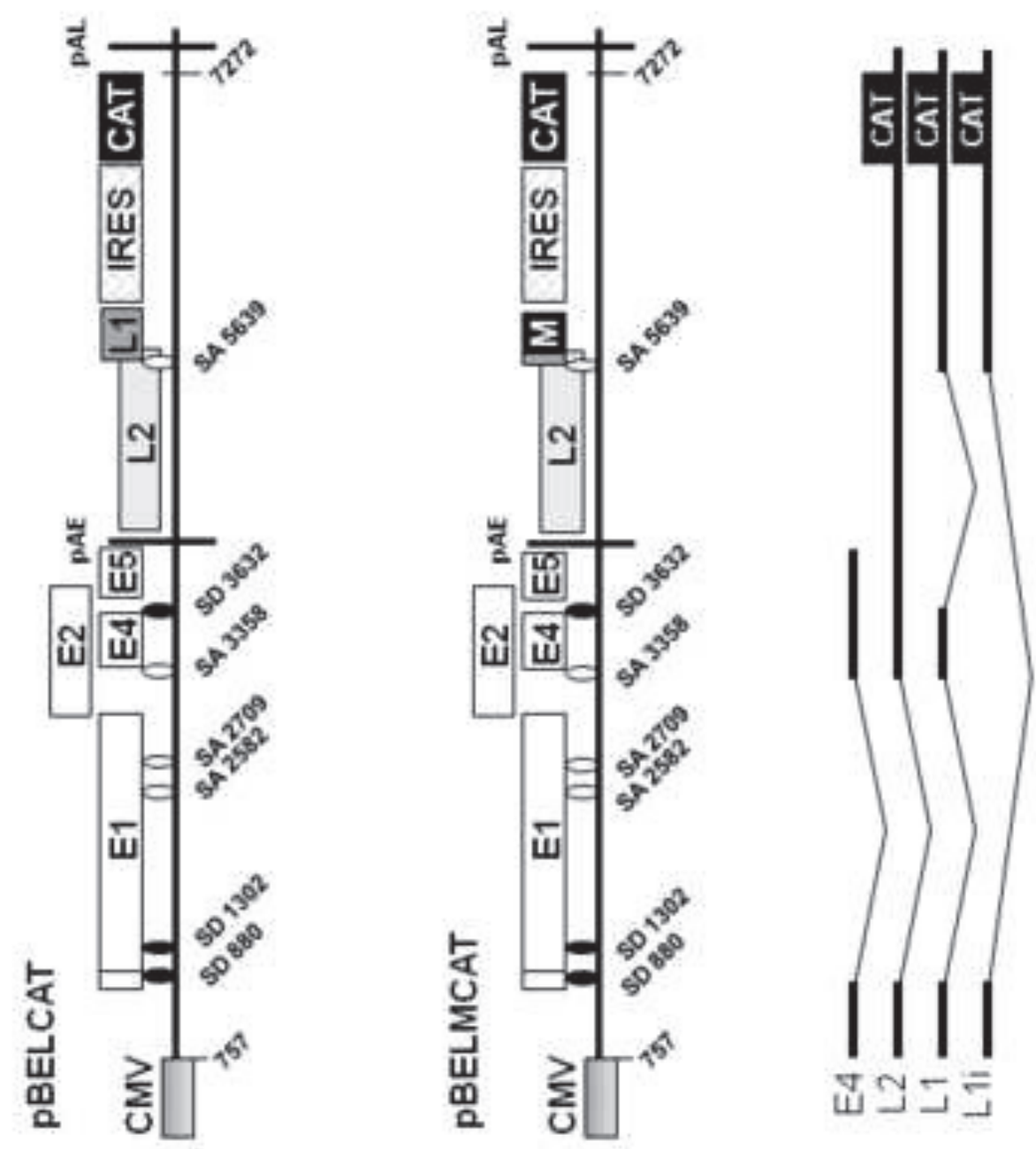

$\frac{0}{0}$
$\frac{0}{0}$
$\frac{0}{4}$ 

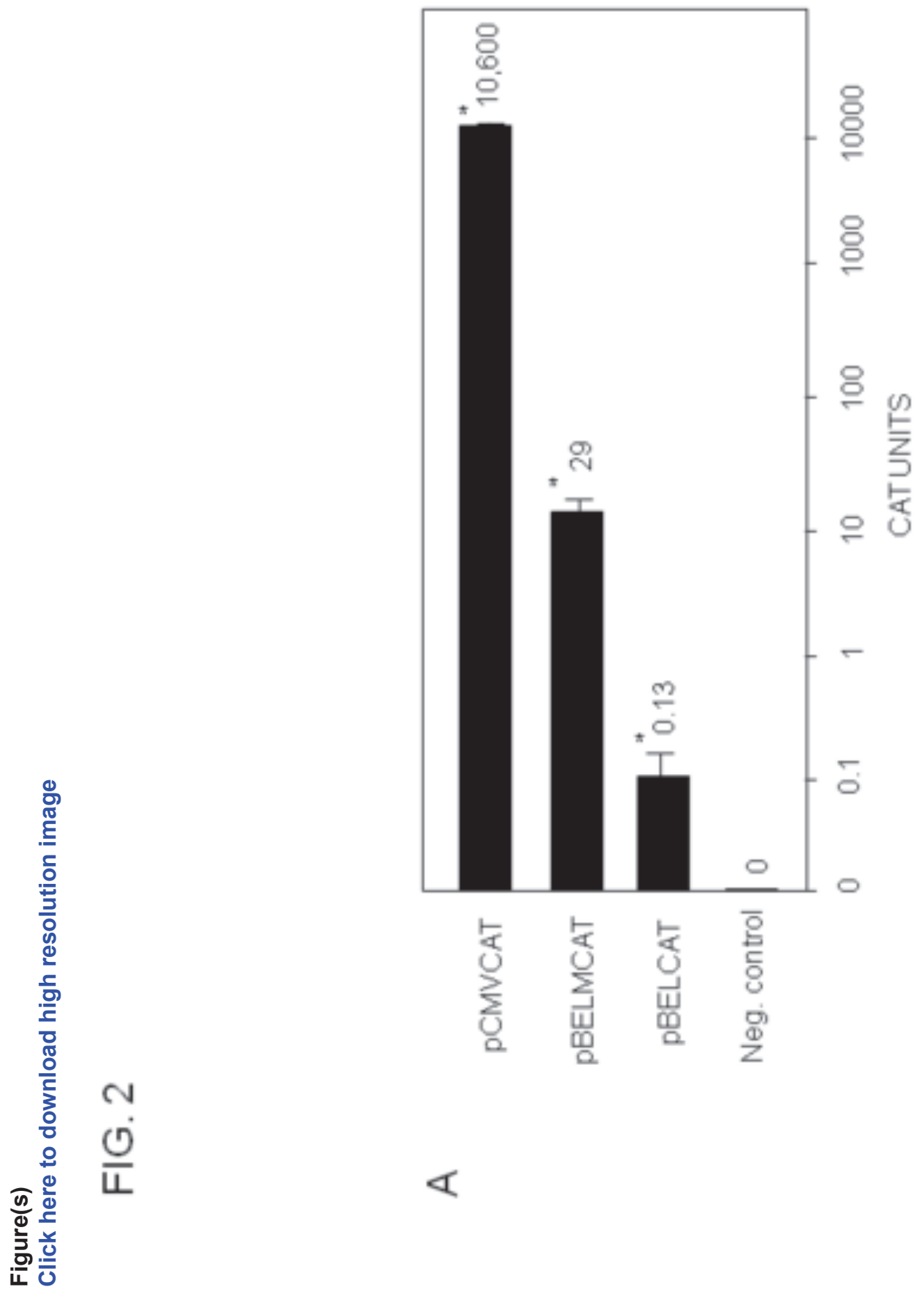

c 

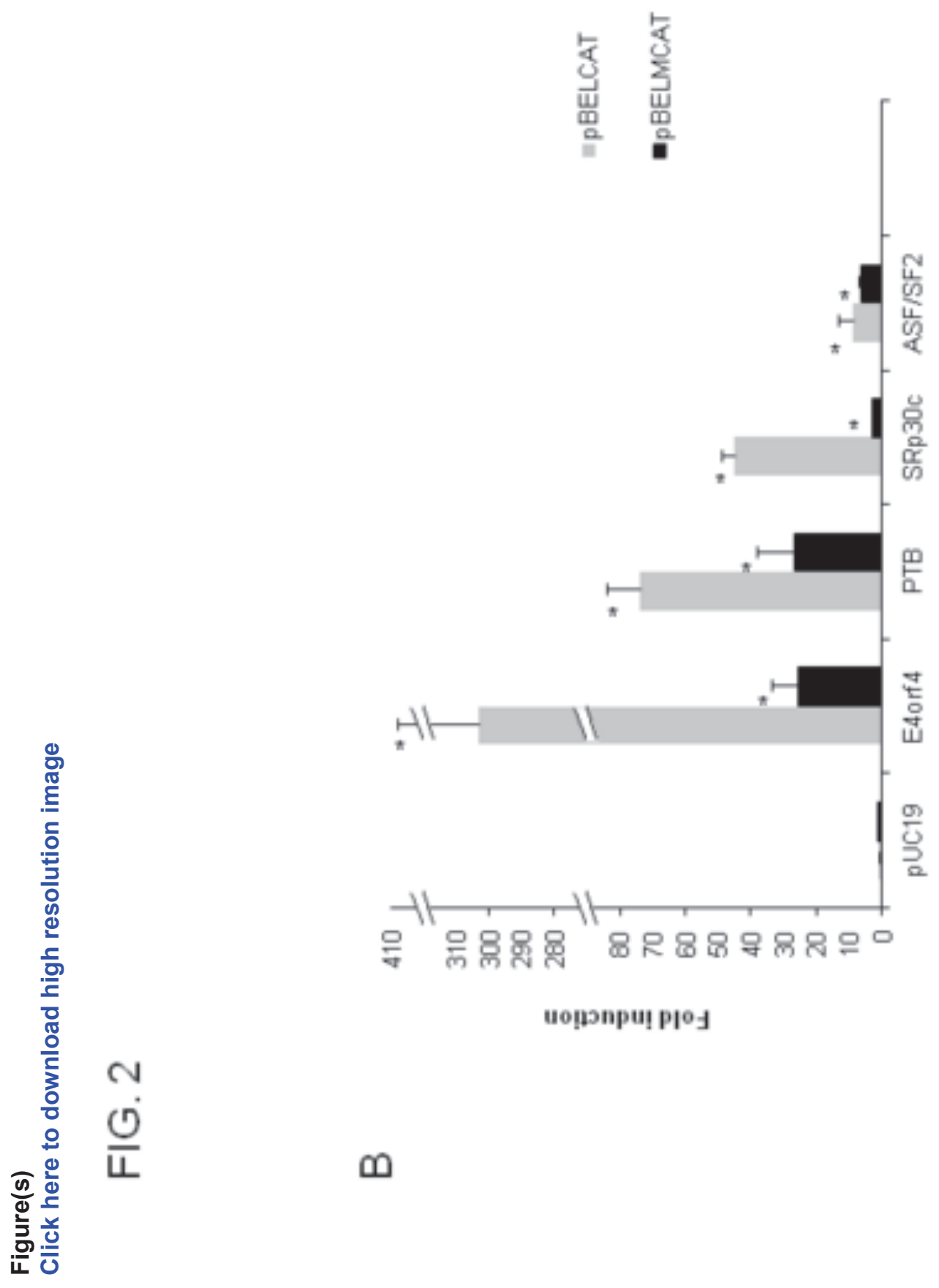

uoџsnpu! Pjo-

๓ 


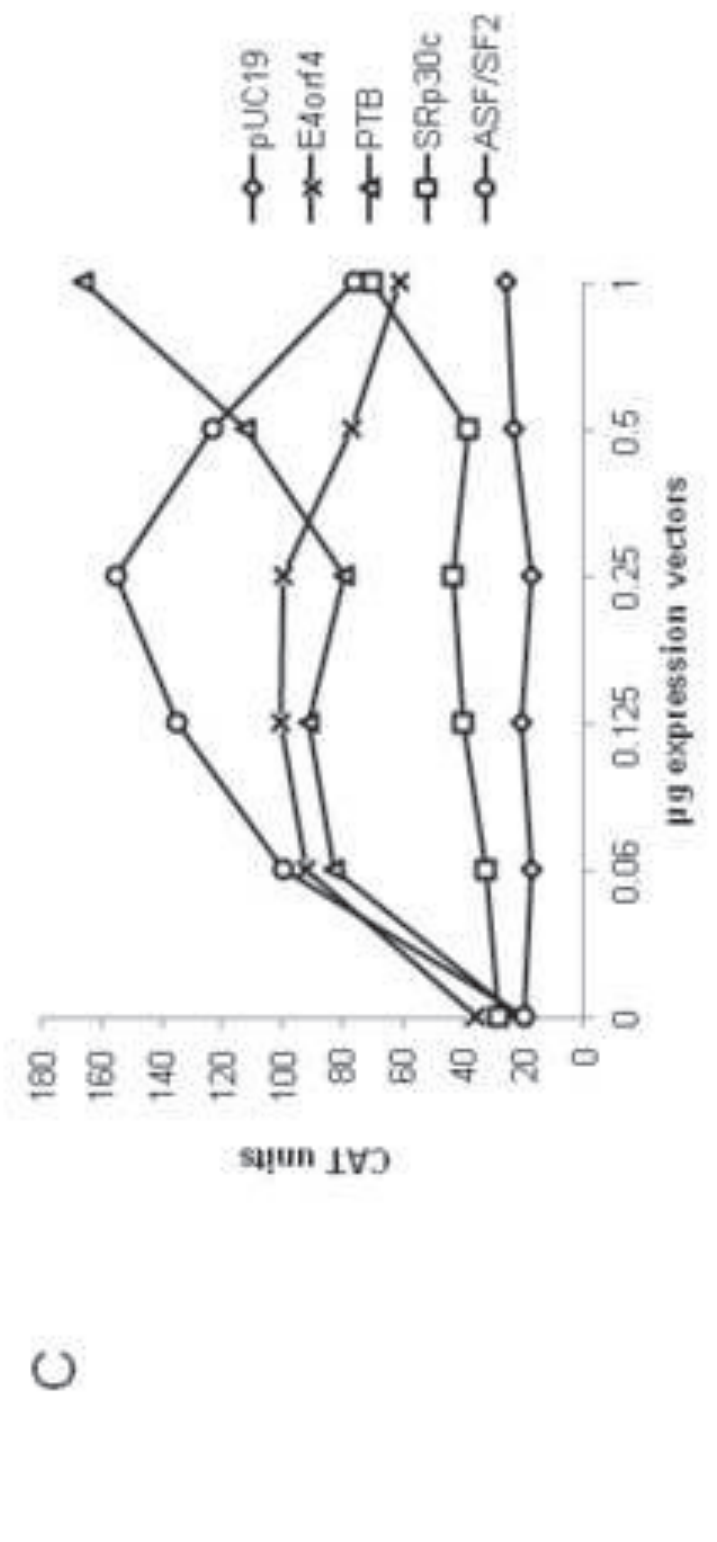



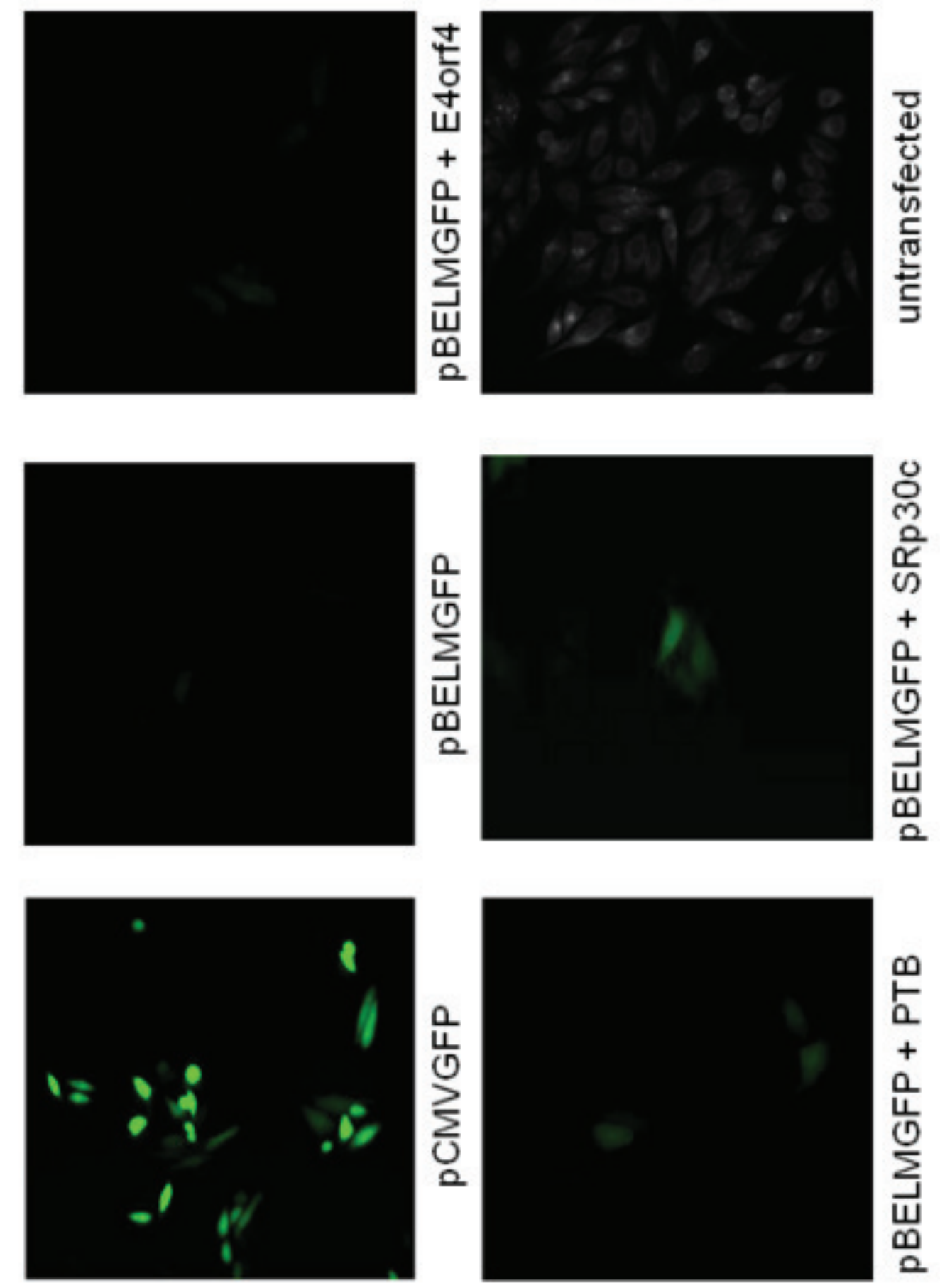

$<$

ए)

은

흔 은

i⿺ 


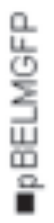

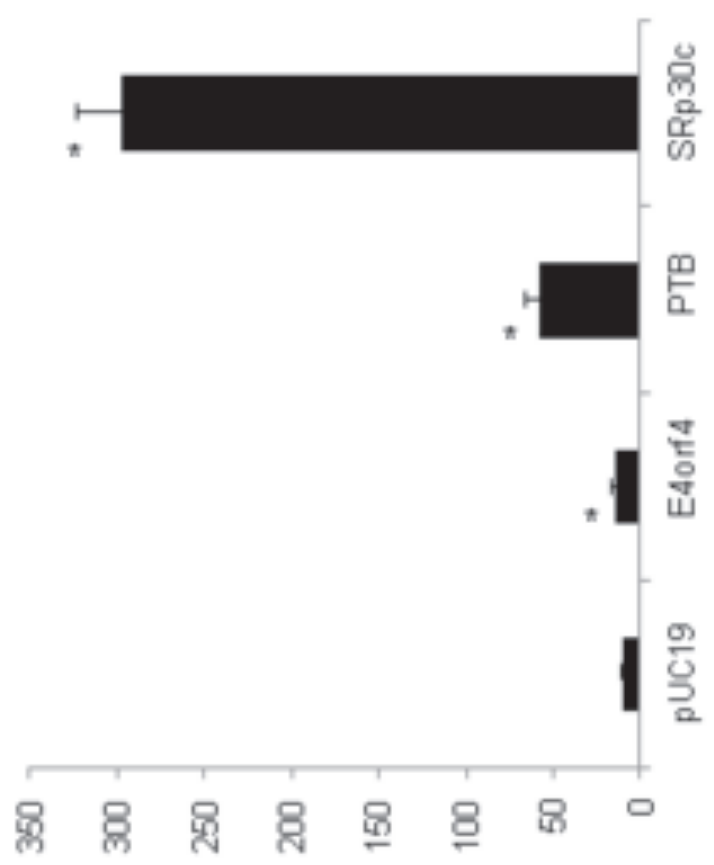

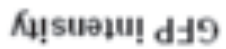

임 


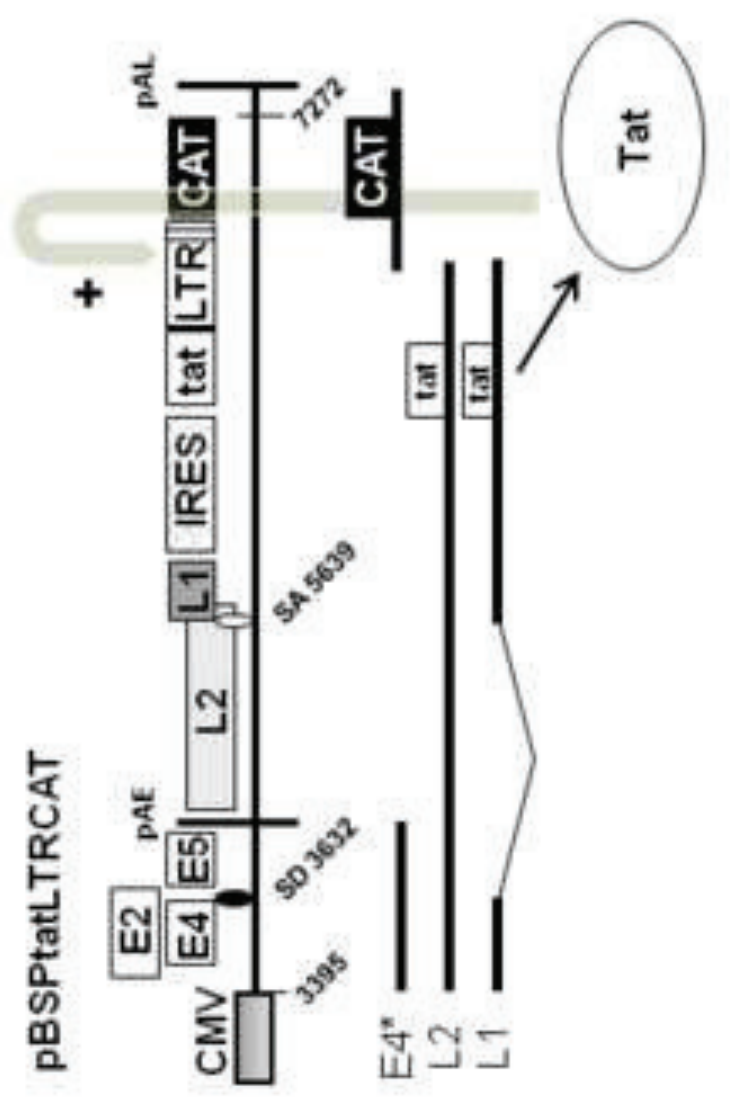

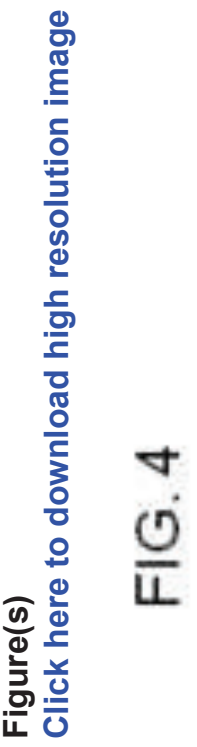
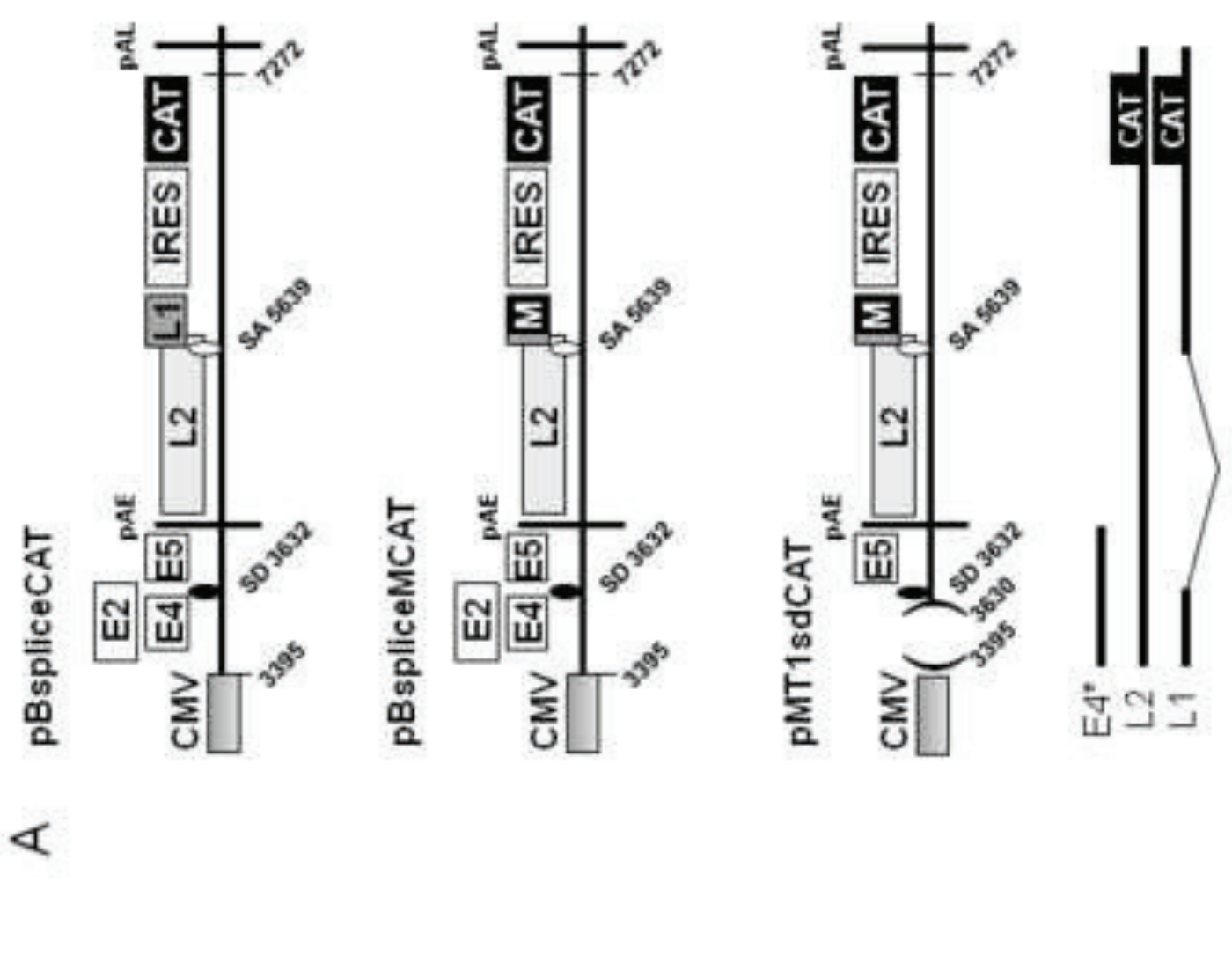


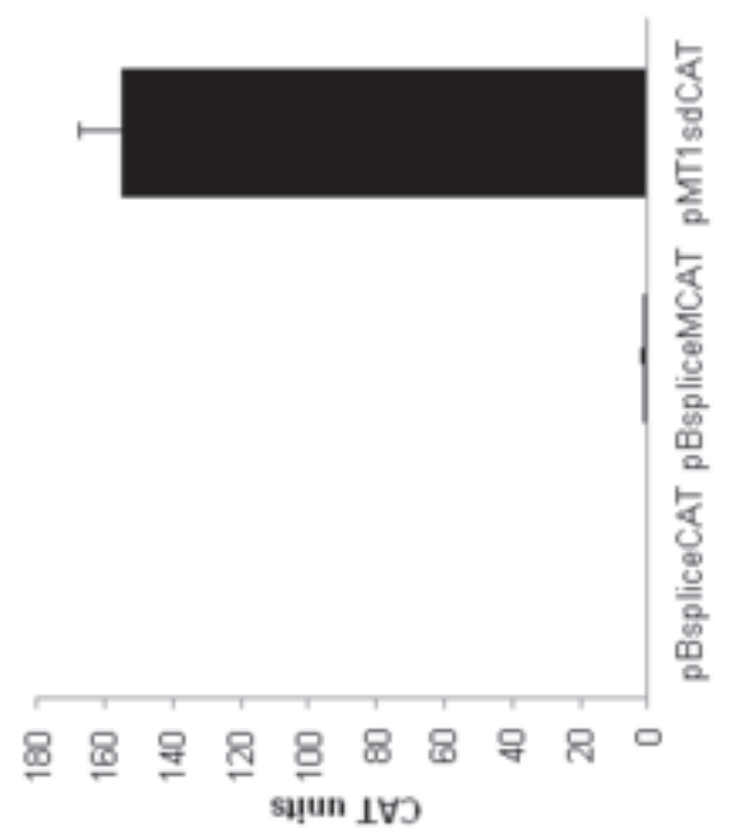

象 


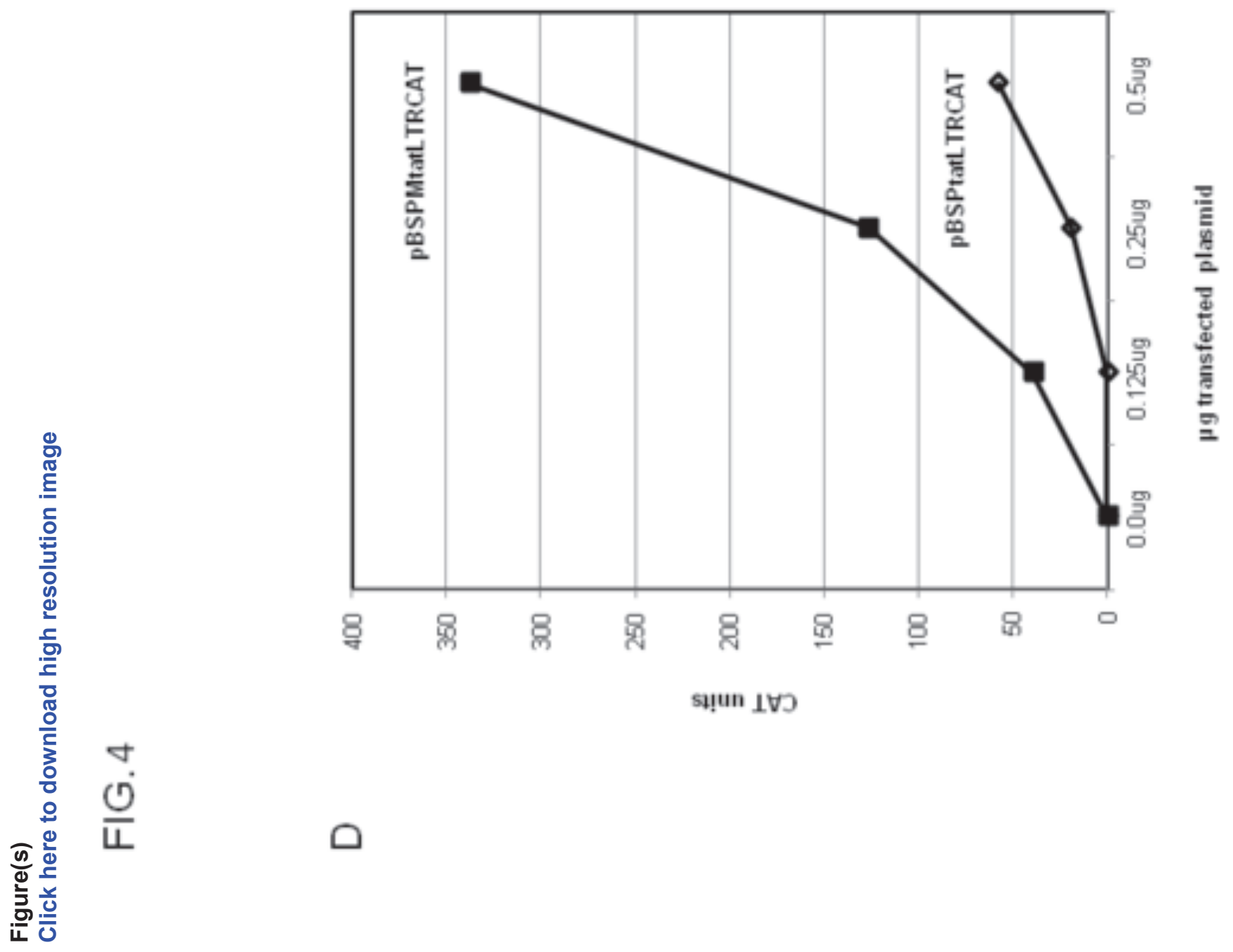

s!̣un $1 \forall 0$

$\frac{\nabla}{4}$

口 

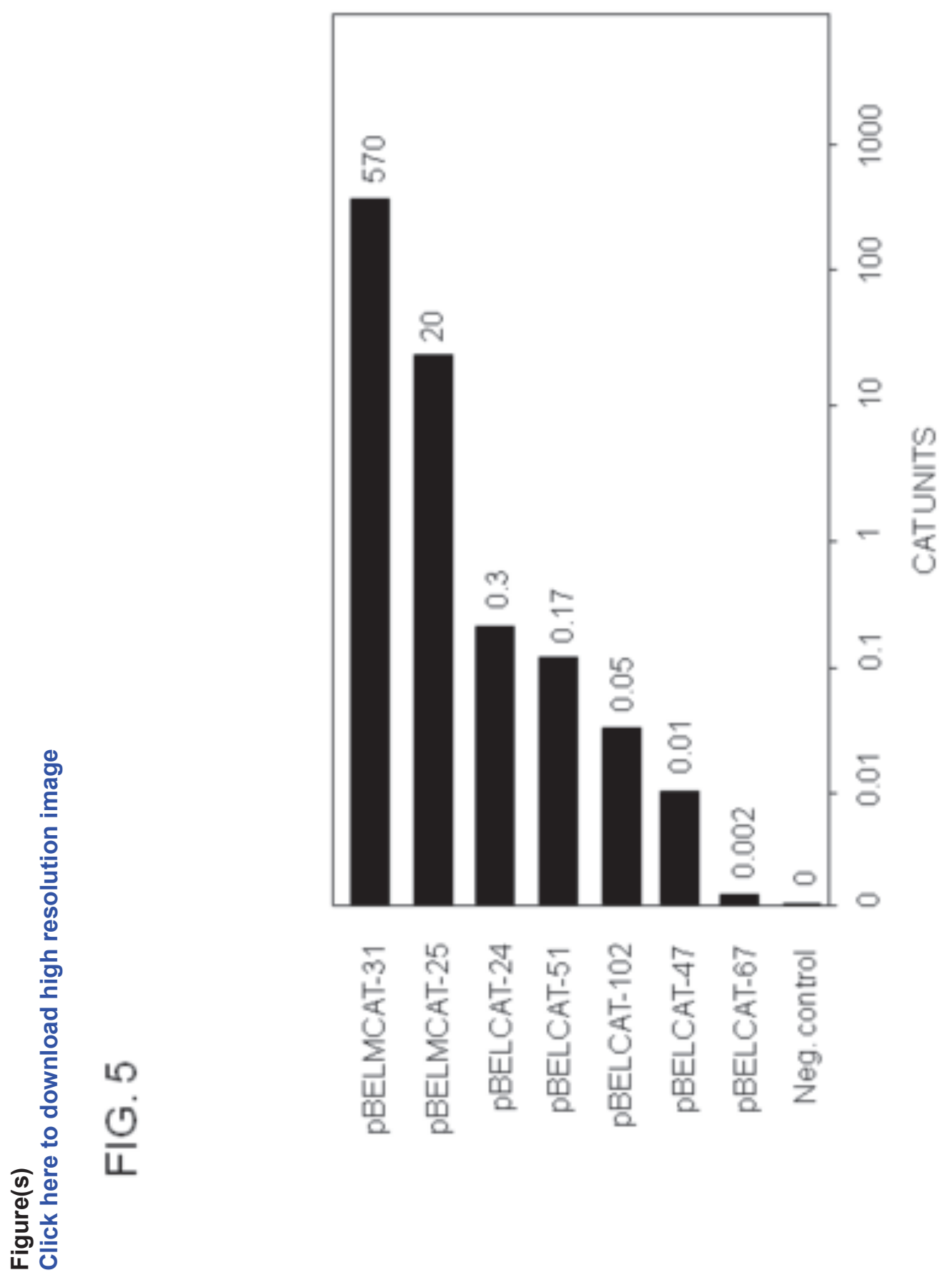


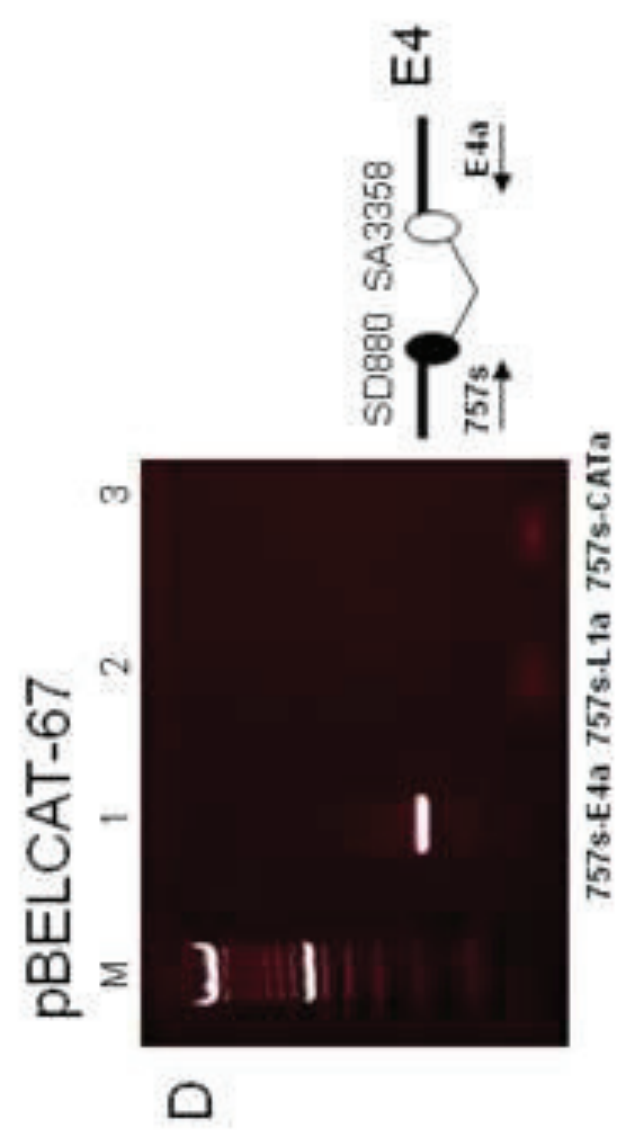

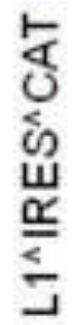

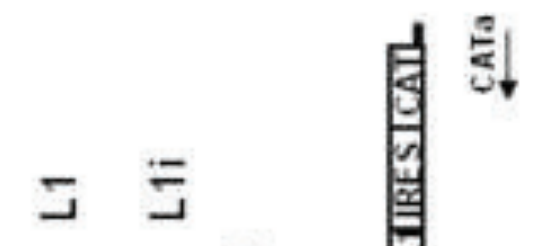

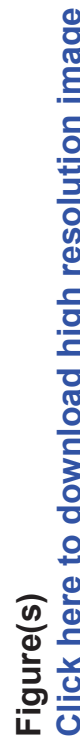
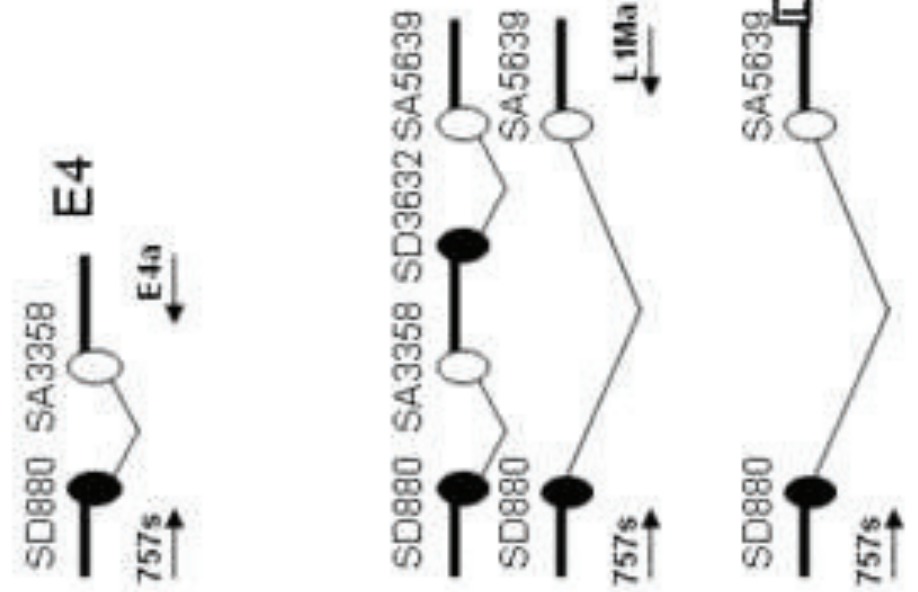

6
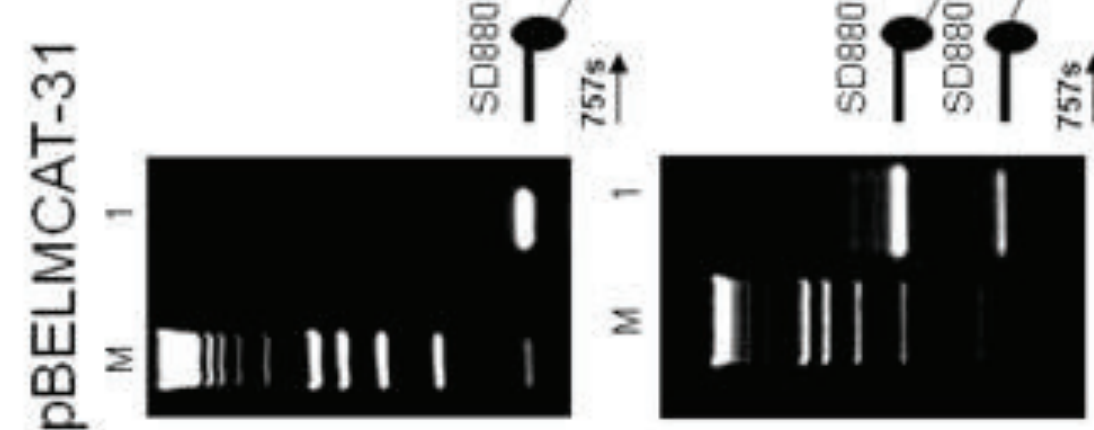

$\omega$

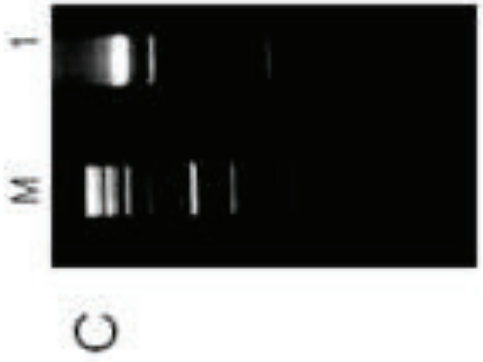



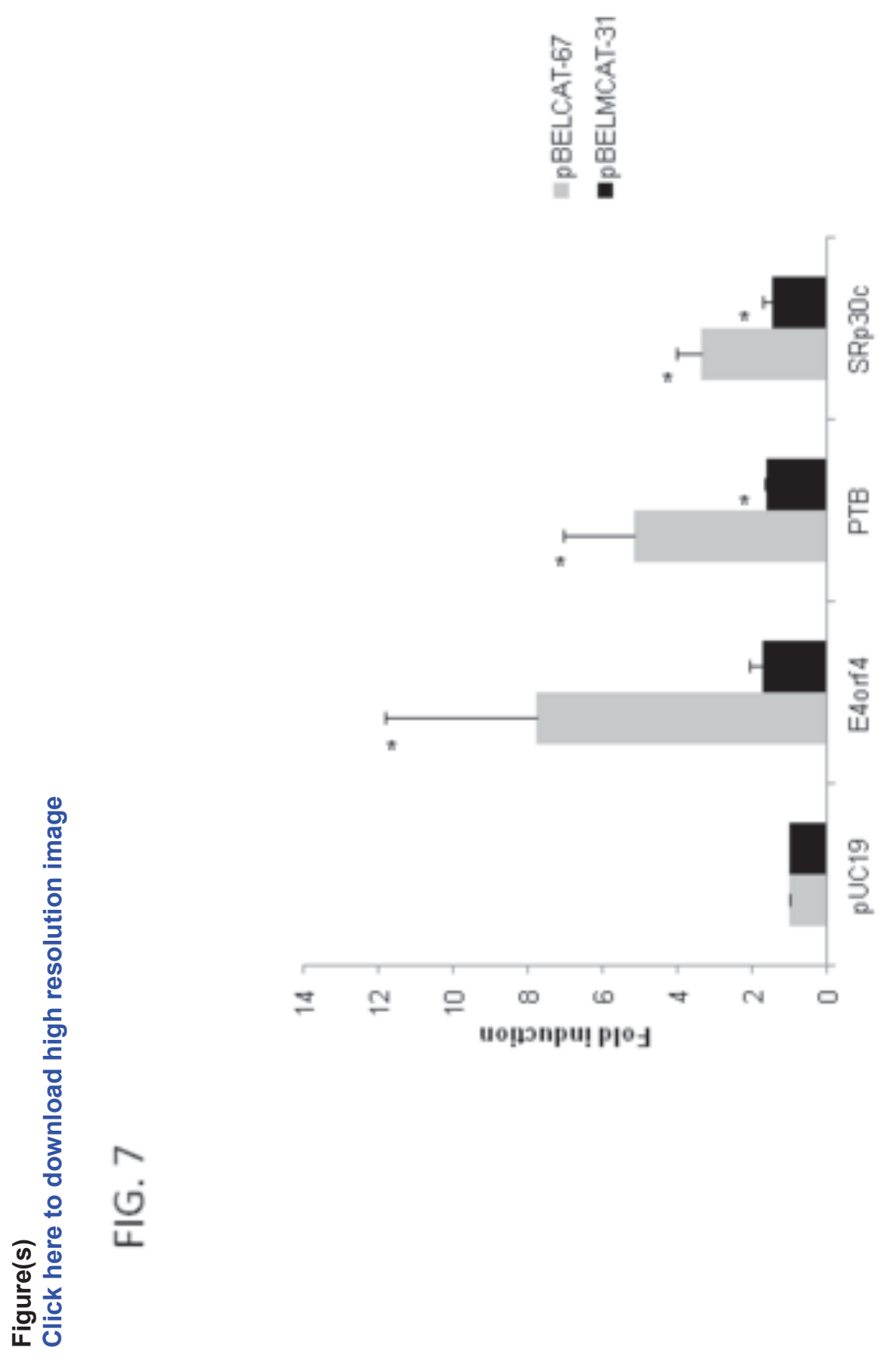


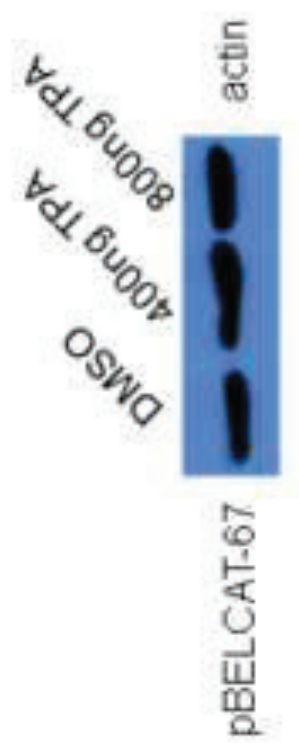

需

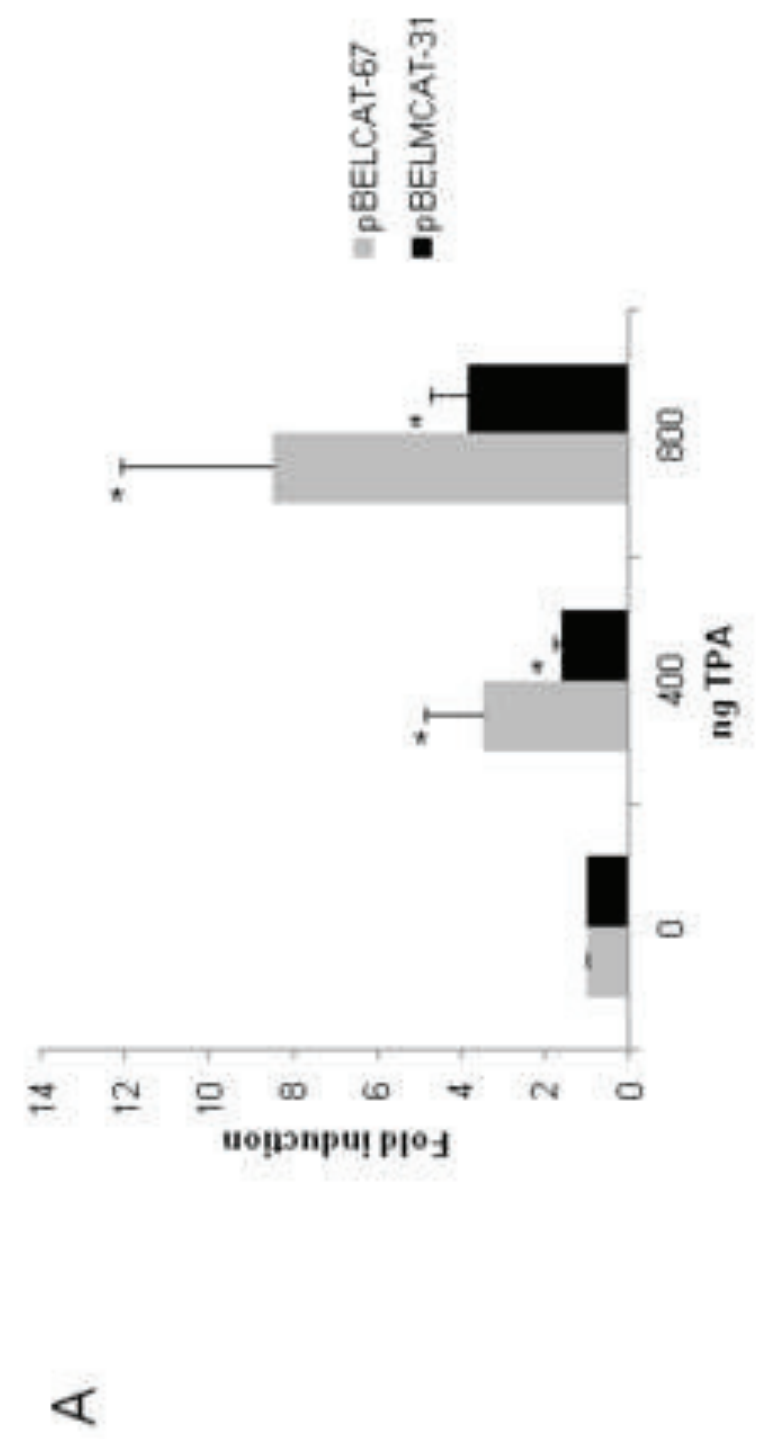




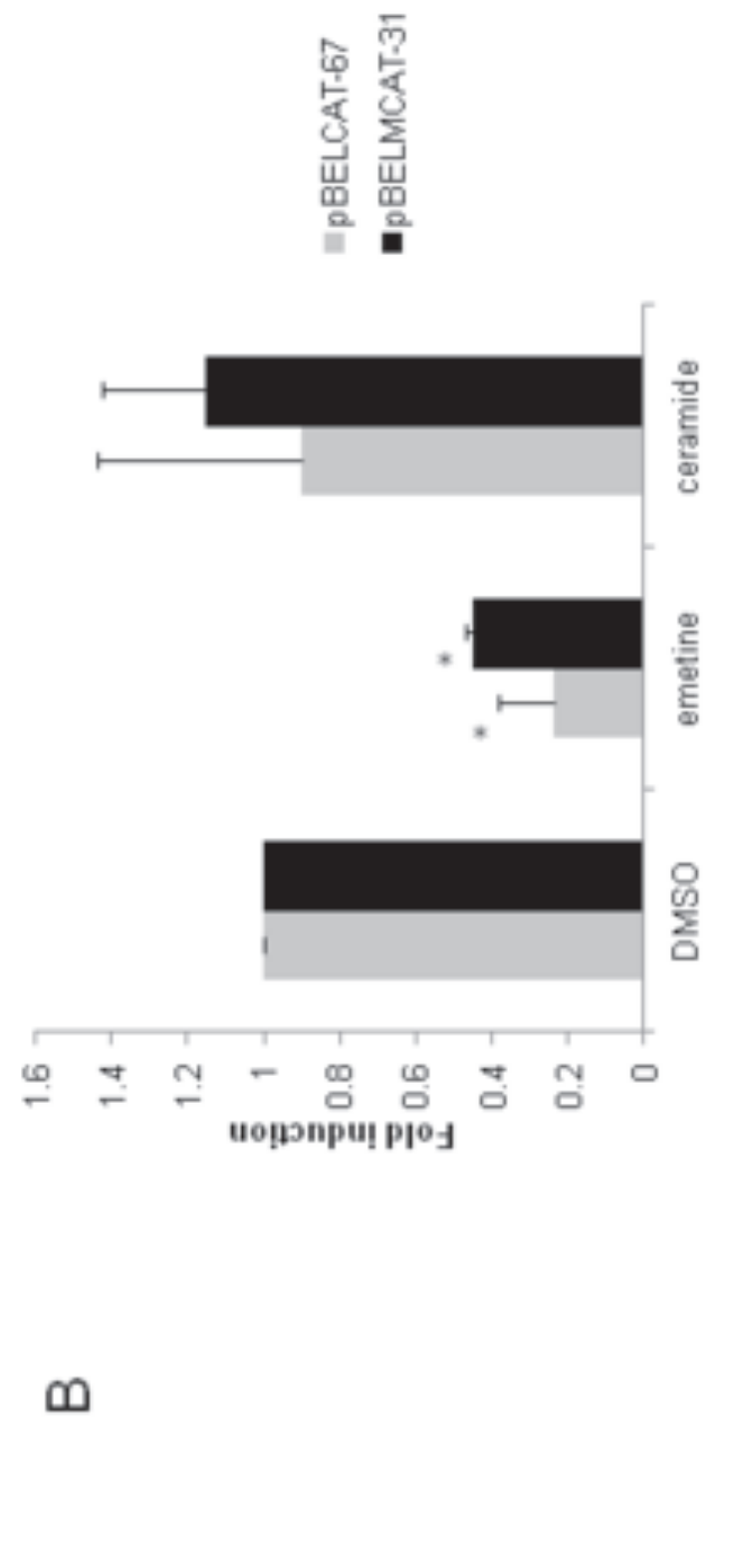




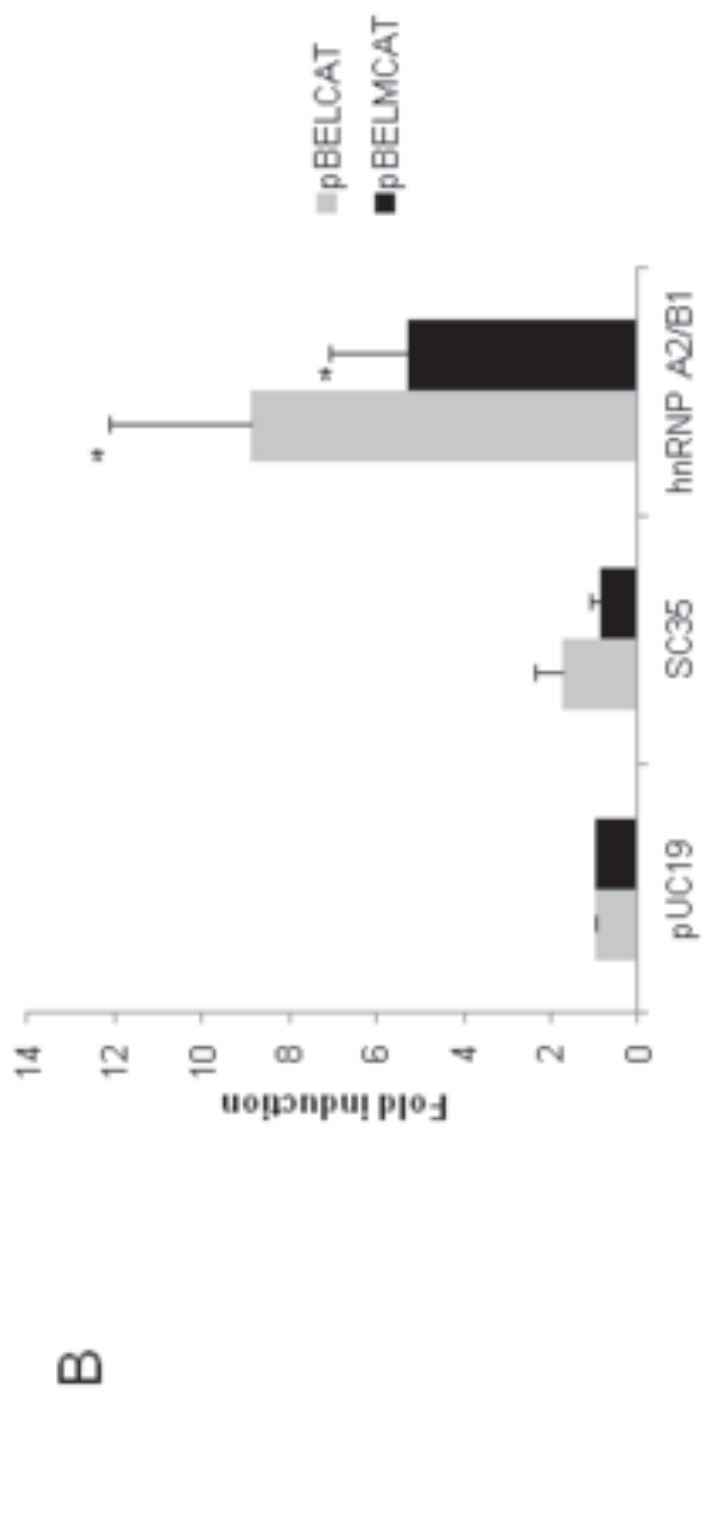




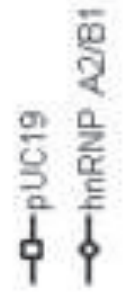

窇

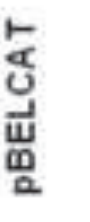

.

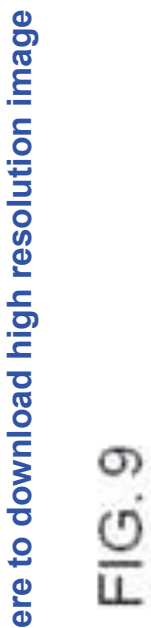

๓)

0
2

i

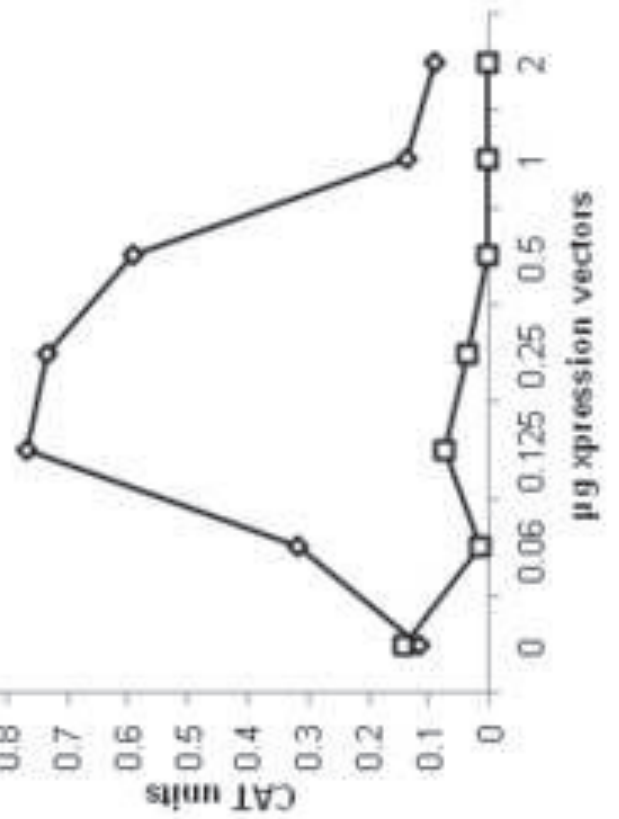

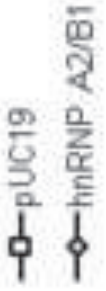

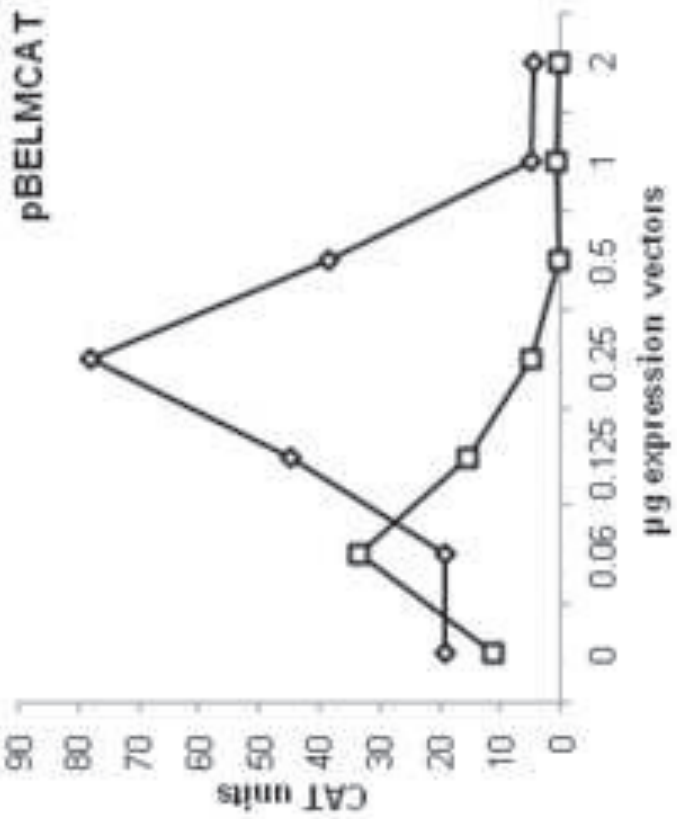


